\title{
NELL-1 regulates the matrisome to alter osteosarcoma disease progression
}

Qizhi Qin Ph.D., ${ }^{1}$ Mario Gomez-Salazar Ph.D., ${ }^{1}$ Robert J. Tower Ph.D., ${ }^{2}$ Leslie Chang M.D., ${ }^{1}$ Carol D. Morris M.D., ${ }^{2}$ Edward F. McCarthy M.D., ${ }^{1}$ Kang Ting, DMD, DMedSc, ${ }^{3}$ Xinli Zhang, M.D., Ph.D., ${ }^{4}$ Aaron W. James, M.D., Ph.D., ${ }^{1 *}$

${ }^{1}$ Department of Pathology, Johns Hopkins University, Baltimore, MD 21205

${ }^{2}$ Department of Orthopaedics, Johns Hopkins University, Baltimore, MD 21205

${ }^{3}$ Forsyth Institute, Cambridge, MA 02142

${ }^{4}$ Section of Orthodontics, Division of Growth and Development, School of Dentistry, University of California, Los Angeles, Los Angeles, CA, 90095

*Corresponding Author:

Aaron W. James, M.D., Ph.D., 720 Rutland Avenue, Room 524A, Baltimore, MD 21205, Phone: (410) 502-4143, Email: awjames@jhmi.edu

Running Title: NELL-1 signaling in osteosarcoma

Keywords: NELL-1, Nel-like protein 1, Neural epidermal growth factor-like 1, osteosarcoma, osteosarcomagenesis, bone tumor, tumor invasion, FAK signaling 


\begin{abstract}
Sarcomas produce abnormal extracellular matrix (ECM) which in turn provides instructive cues for cell growth and invasion. Neural EGF Like-Like molecule 1 (NELL1) is a secreted glycoprotein characterized by its non-neoplastic osteoinductive effects, yet highly expressed in skeletal sarcomas. Here, NELL1 gene deletion markedly reduced invasive behavior across human osteosarcoma (OS) cell lines. This resulted in reduced OS disease progression, inhibited metastatic potential and improved survival in a xenograft model. These observations were recapitulated with Nell1 conditional knockout in mouse models of p53/Rb driven sarcomagenesis, including reduced tumor frequency, and extended tumor free survival. Transcriptomic and phospho-proteomic analysis demonstrated that NELL1 loss skews the expression of matricellular proteins associated with reduced FAK signaling. Culture on OS enriched matricellular proteins reversed phenotypic and signaling changes among NELL1 knockout sarcoma cells. These findings in mouse and human models suggest that NELL1 expression alters the sarcoma matrix, thereby modulating cellular invasive potential and prognosis. Disruption of NELL1 signaling may represent a novel therapeutic approach to short circuit sarcoma disease progression.
\end{abstract}




\section{Introduction}

Sarcomas are a broad group of malignant neoplasms that arise from mesenchymal cells origin in soft tissue and bone ${ }^{1,2}$. Emerging molecular findings suggest that mechanical and chemical properties of the tumor microenvironment act together to accelerate sarcoma disease progression

3. Within the tumor microenvironment, structural extracellular matrix (ECM) proteins play crucial role in cell surface receptor signaling ${ }^{4,5}$, which in turn may regulate sarcoma cell invasive and metastatic potential ${ }^{6,7,8,9,10}$. Osteosarcoma (OS), the most common primary malignancy of bone ${ }^{11,12,13,14}$, is defined by its pathogenic osseous ECM ${ }^{15}$. Several studies have demonstrated OS matrix is extensively altered, including changes in collagens and proteoglycans ${ }^{15,16}$. In particular, high expression of several sarcomatous matrix proteins has been associated with poor response to chemotherapy and poor prognosis in clinical studies of OS $17,18,19,20$.

NELL1 (Neural EGFL like 1) is a secreted osteoinductive protein which has bone anabolic ${ }^{21,22,}$ 23, 24 and anti-osteoclastic effects ${ }^{25,26}$. NELL1 can significantly stimulate mesenchymal stromal cell proliferation and osteogenic differentiation, until recently NELL1 was simply known to regulate skeletal patterning and induce bone defect healing in small and large animals ${ }^{27,28,29}$. Earlier studies revealed that loss of Nell1 expression or function in mice reduces expression of numerous ECM proteins, as well as proteins involved in cell adhesion and cellular communication ${ }^{30}$. Notably, NELL1 expression has been detected in bone tumors and cartilageforming tumors ${ }^{31}$. With these recent insights, it is likely that the cellular effects of NELL1 are much more pleiotropic than once understood. Nevertheless the biologic implications of NELL1 signaling in osteosarcomagenesis and/or disease progression have been until this point unknown. 
Here, we sought to define the regulatory role of NELL1 in sarcoma pathogenesis. CRISPR/Cas9 mediated NELL1 gene deletion markedly reduced the malignant phenotype across human OS cell lines. NELL1 knockout significantly slowed OS disease progression, blunted metastatic potential, and improved survival in a xenograft model. Similar observations were identified with Nell1 gene deletion in a $\mathrm{p} 53 / \mathrm{Rb}$ driven osteosarcomagenesis mouse model. Transcriptomic and proteomic analysis demonstrated NELL1 knockout skews the expression of key matricellular proteins associated with reduced FAK signaling. These findings in mouse and human osteosarcoma suggest that NELL1 signaling positively regulates multiple aspects of OS disease progression in part via alterations in the sarcomatous ECM, and that disruption of NELL1 signaling may represent a novel therapeutic approach. 


\section{Results}

Cell autonomous effects of NELL1 gene deletion in osteosarcoma

First, expression of NELL1 transcripts was observed to be a conserved feature across all human OS cell lines examined, a finding in agreement with prior observations (Fig. 1A) ${ }^{31}$. Gene deletion studies were first performed using the 143B cell line, generating six NELL1 KO clones using CRISPR/Cas9. Knockout was confirmed using qRT-PCR, T7 endonuclease I assay (Supplementary Fig. S1) and immunocytochemistry (Fig. 1B). In comparison to vector control, multiple cellular effects were observed among NELL1 KO cell clones, including reduced proliferation (Fig. 1C, mean 34.9\% reduction at 72 h), attachment (Fig. 1D, E, mean 31.9\% reduction at 5 h), and invasion (Fig. 1F, G, 25.1-69.1\% reduction across clones). Similar findings were observed with analysis of a polyclonal NELL1 KO 143B cell population (Supplementary Fig. S2), and indeed similar assessments across five other available OS cell lines recapitulated these findings (Fig. 1H-J). Overexpression studies were performed, in which adenoviral delivery (Ad-NELL1) led to partial restoration of gene expression and near complete restoration of attachment and invasion potential among NELL1 KO 143B sarcoma cells (Fig. 1K-M). These data confirmed that the NELL1 gene plays a crucial role in maintaining cellular proliferation, attachment, and invasion potential in OS cells.

\section{NELL1 knockout mitigates OS disease progression}

NELL1 KO 143B clones were next implanted in an orthotopic xenograft model in NOD scid mice (Fig. 2A). In relation to control, tumor growth was impeded as assessed by serial caliper measurements (Fig. 2B, 66.9\% reduction in tumor size at study endpoint). Findings were confirmed in an independent clone of knockout tumor cells (Supplementary Fig. S3, 89.2\% 
reduction in tumor size). MRI confirmed a $57.1 \%$ and $66.1 \%$ reduction in tumor size at 14 and 28 d post-implantation (Fig. 2C). Histologic examination of primary tumors demonstrated complete loss of NELL1 immunoreactivity among NELL1 KO xenograft tumor cells (Fig. 2D), accompanied by a reduction in the proliferative index of NELL1 KO implants (Fig. 2E, 67.5\% reduction in Ki67 labeling). Tumor associated angiogenesis also showed a notable reduction among NELL1 KO implants (Fig. 2F, 74.9\% reduction in CD31-positive vessel area), in line with prior reports of the angiogenic effects of NELL1 signaling ${ }^{32,33,34}$. In order to confirm the impact of NELL1 on invasion and metastasis, pulmonary metastatic burden was assessed by serial sections of lung fields. Results indicated complete absence of lung metastasis among NELL1 KO tumors at $28 \mathrm{~d}$ post-inoculation (Fig. 2G, H). In a separate cohort of animals, mice with NELL1 KO tumors demonstrated prolonged overall survival (Fig. 2I, 89.6\% increase in median overall survival). Reduction in metastatic potential among NELL1 KO sarcoma cells was further verified using tail vein injection, in which an $81.1 \%$ reduction in pulmonary burden was observed (Fig. 2J, K). Together, our data demonstrates that NELL1 gene deletion slows OS tumor growth and mitigates metastasis in a xenograft model.

\section{NELL1 gene deletion impedes osteosarcomagenesis}

The consequences of NELL1 gene deletion were next examined in two murine OS models ${ }^{35,36}$. Firstly, mouse BMSCs were isolated from $p 53^{\mathrm{fl} / f \mathrm{l}} ; R b^{\mathrm{fl} / \mathrm{fl}}(\mathrm{DKO})$ or $p 53^{\mathrm{fl} / \mathrm{fl}} ; R b^{\mathrm{fl} / \mathrm{fl} l} ; N e l l 1^{\mathrm{fl} / \mathrm{fl}}(\mathrm{TKO})$ mice, recombination performed via adenovirus-mediated Cre delivery and the consequences examined in vitro and after periosteal transplantation (Fig. 3A). As expected, gene knockout of $p 53$ and $R b$ resulted in an increased proliferative and invasive phenotype in comparison to vector control (Supplementary Fig. S4). In comparison to DKO tumor cells, TKO cells demonstrated 
reduced colony formation (Fig. 3B, 33.3\% reduction), reduced cellular attachment (Fig. 3C, $27.5 \%$ and $19.8 \%$ reduction at 3 and $5 \mathrm{~h}$, respectively), and reduced tumorsphere formation efficiency (Fig. 3D, 35.9\% reduction at 5 d). DKO and TKO cells were next orthotopically implanted in NOD scid mice, and sarcomagenesis and growth were monitored (Fig. 3E-H). Tumor formation rates were significantly reduced among TKO implants $(25.0 \%$ incidence in comparison to $100 \%$ incidence among DKO implants, Supplementary Table S1). Among those implants with tumor formation, tumor size was significantly lower in TKO cell implants (Fig. 3E, $76.7 \%$ reduction in tumor size). Histological analysis confirmed an osteosarcoma-like appearance of all tumors, and confirmed complete loss of NELL1 immunoreactivity among TKO tumor cells (Fig. 3F). In similarity to prior findings, Nell1 gene deletion demonstrated a reduction in proliferative index and vascularity among tumors, assessed by Ki67 and CD31 immunostaining (Fig. 3G, 86.9\% reduction in Ki67, and $71.1 \%$ reduction in CD31 immunostaining). Moreover, tumor-free survival was significantly prolonged in mice with TKO implants, with a hazard ratio (HR) of 0.115 (Fig. 3H).

Secondly, the same transgenes were used to monitor spontaneous osteosarcomagenesis, now utilizing the osteoblast specific Osteocalcin-Cre line ${ }^{37}$. Animals with conditional knockout of $p 53$ and $R b\left(p 53^{\mathrm{fl} / \mathrm{fl}} ; R b^{\mathrm{fl} / \mathrm{fl}}\right.$;OC-Cre, referred to as control) were compared to animals with conditional knockout of $p 53, R b$ and $N e l l 1\left(p 53^{\mathrm{fl} / / \mathrm{fl}} ; R b^{\mathrm{fl} / f 1} ; N e l l 1^{\mathrm{fl} / \mathrm{fl}} ; \mathrm{OC}-\mathrm{Cre}\right.$, referred to as $N e l l 1^{\mathrm{OC}}$ cKO, Fig. 3I). Mice heterozygote for $R b$ were also examined for tumor incidence. Tumor formation rates were significantly reduced among $N e l l 1^{\mathrm{OC}} \mathrm{cKO}$ animals $(15.8 \%$ incidence in $N e l l 1^{\mathrm{OC}} \mathrm{cKO}$ animals in comparison to $52.4 \%$ incidence among control animals, Supplementary

Table S2). Radiographic and histologic appearance across tumors was consistent with 
osteosarcoma (Fig. 3J, tumor locations summarized in Supplementary Table S3). NELL1 immunohistochemical staining confirmed loss of NELL1 within sarcoma cells (Fig. 3K). Immunohistochemical analyses again confirmed reduction in the proliferative index and tumor associated vasculature among tumors in Nell1 $^{\mathrm{OC}} \mathrm{cKO}$ animals (Fig. 3L, 85.2\% reduction in $\mathrm{Ki} 67$, and $66.1 \%$ reduction in $\mathrm{CD} 31$ immunostaining). Nell ${ }^{\mathrm{OC}} \mathrm{cKO}$ animals showed prolonged tumor-free survival (Fig. 3M, Supplementary Table S3, median tumor-free survival of 398 days in $\mathrm{Nell1}^{\mathrm{OC}} \mathrm{cKO}$ versus 146.5 days in controls). Collectively, Nell1 loss impeded p53/Rb induced OS sarcomagenesis, but also reduced tumor growth and improved disease free survival in mouse models.

\section{NELL1 gene deletion shifts the sarcoma matrisome}

Differences in gene expression profile were next investigated using bulk RNA sequencing across 4 clones of NELL1 KO and VC 143B cells. Clear separation between gene expression profiles was observed between NELL1 KO and control cells, as assessed by principal component analysis and volcano plot (Supplementary Fig. S5A, B). QIAGEN Ingenuity Pathway Analysis (IPA) showed that multiple signaling pathways were downregulated in NELL1 KO cells, including for instance integrin-linked kinase (ILK), ERK/MAPK and VEGF signaling (Fig. 4A, see Supplementary Tables S4, 5 for a complete list). Next, pathway analysis of differentially expressed genes (DEGs) revealed Gene ontology (GO) term enrichment in extracellular matrix (ECM) organization, angiogenesis, integrin-mediated signaling pathway, and ECM disassembly were downregulated in NELL1 KO cells (Fig. 4B, see Supplementary Table S6, 7 for most downregulated and upregulated GO terms). Heat maps revealed differences in expression profile of OS related genes among NELL1 KO and VC cells, including for example $M D M 2, C D K 4$, and 
CD44 among others (Supplementary Fig. S5C) ${ }^{38,39,40}$. Next, deletion of NELL1 in OS cells was further validated by downstream signaling-related gene expression, shown by heatmap and cumulative module scoring (Fig. 4C-F). Although in other contexts canonical BMP and Wnt signaling pathway activation are known to be downstream of NELL1 signaling ${ }^{23,41}$, no significant change in either pathway was observed with NELL1 gene deletion (Fig. 4C, D). Instead, significant reductions in gene modules related to ECM-receptor interaction and FAK signaling were observed among NELL1 KO sarcoma cells (Fig. 4E, F).

In order to further evaluate differences with NELL1 gene deletion, a reverse phase protein array was performed. A clear separation between protein profiles was observed when comparing NELL1 KO and VC cells, as assessed by principal component analysis and volcano plot (Supplementary Fig. S6A, B). Again, pathway analysis of downregulated DEGs revealed GO term enrichment in NELL1 KO cells associated with the regulation of cellular proliferation, migration, adhesion and cell spreading (Fig. 4G, see Supplementary Table S9, 10 for most downregulated and upregulated GO terms). Next, we focused on the ECM-related gene expression and FAK signaling. Having observed prominent shifts in terms related to cell-ECM interaction within the transcriptome and proteome of NELL1 KO sarcoma cells, we next examined specific misexpressed ECM transcripts within NELL1 KO cells (Fig. 4H). Analysis showed significant decrease in expression across several ECM components including for example FN1 (Fibronectin 1), LAMC2 (Laminin subunit gamma 2), and COL6A3 (Collagen type VI alpha 3 chain) with NELL1 gene deletion (Fig. 4H). Proteomic analysis confirmed a downregulation of FN1, as well as decreased phosphorylation of FAK and Src in NELL1 KO cells (Fig. 4I). Thus, a transcriptomic-proteomic analysis suggested that deletion of NELL1 in 
sarcoma cells alters the ECM profile, including prominent reductions in FN1 and Laminin, alterations in pathways associated with cell-ECM interaction, and a reduction FAK signaling activity.

\section{Matrix components can reverse phenotypic changes with NELL1 gene deletion}

Having observed that NELL1 gene deletion among 143B sarcoma cells resulted in deficits in key matricellular proteins and reduced FAK signaling activation, we next sought to confirm these findings across in vivo models. In a candidate fashion, fibronectin (FN1) and laminin (LAM) expression among 143B xenografts was assessed by immunofluorescent staining (Fig. 5A). Immunostaining showed diffuse FN1 and LAM immunoreactivity in control tumors, staining for both proteins was significantly reduced in NELL1 KO tumors (Fig. 5A, 69.4\% and 73.7\% reduction in FN1 and LAM, respectively). Corresponding activation of FAK signaling was next accessed by immunofluorescent staining for FAK and pFAK across 143B sarcoma samples. Among NELL1 KO sarcoma sections, decreased pFAK and retained FAK immunoreactivity was observed in comparison to control tumors (Fig. 5B, no significant differences in FAK, 58.3\% reduction in $\mathrm{pFAK}$, and $54.9 \%$ reduction in $\mathrm{pFAK} / \mathrm{FAK}$ staining). These findings regarding altered sarcoma matrix were likewise observed in the murine spontaneous OS model induced by p53/Rb deletion (Fig. 5C, D). Here, sarcomas among $N E L L 1^{\mathrm{OC}} \mathrm{cKO}$ animals demonstrated a $74.9 \%$ and $71.6 \%$ reduction in FN1 and LAM immunofluorescent staining across serial sections (Fig. 5C), associated with a $71.6 \%$ reduction in pFAK staining and $66.7 \%$ reduction in pFAK/FAK immunostaining in relation to control tumor tissues (Fig. 5D). This data further correlated NELL1 gene deletion with shifts in sarcoma associated ECM composition and a corresponding reduction in FAK signaling. 
Next, the extent to which the matricellular proteins FN1 and LAM could restore FAK signaling and alter cellular behavior among NELL1 KO 143B cells was assessed (Fig. 5E-I). Here, cell culture flasks were pre-coated with FN1 or LAM $\left(5 \mu \mathrm{g} / \mathrm{cm}^{2}\right)$. First, FAK activation was assessed in NELL1 KO cells by pFAK immunocytochemistry and western blot (Fig. 5E, F). Results confirmed a decrease in FAK phosphorylation among NELL1 KO cells in relation to vector control, which was observed to be restored by supplementation with FN1 or LAM coating (Fig. 5E). This finding was further validated by western blot and semi-quantitation (Fig. 5F,

Supplementary Fig. S8). Further, restoration of FAK signaling activity with either FN1 or LAM coating led to alterations in cell attachment profiles among NELL1 KO sarcoma cells. Here, complete restoration of attachment rate was observed among NELL1 KO sarcoma cells on FN1 or LAM substrates (Fig. 5G). Correspondingly, a similar increase in adhesion-dependent cell spreading (Fig. 5H) and cytoskeletal size (Fig. 5I) was observed among NELL1 KO sarcoma cells when placed on either matrix component. In sum, these data indicate that alterations in the sarcoma matrix composition mediate FAK signaling and tumor cell attachment potential, and implicate NELL1 as an important regulator of this process.

\section{NELL1 expression typifies an aggressive phenotype in human osteosarcoma}

Finally, the critical role of NELL1 signaling in primary human osteosarcoma cells and tissues was examined. First, patient-derived human osteosarcoma cells (HuOS) were isolated and extensive karyotypic abnormalities were observed in the resulting cell isolates (Fig. 6A, B). Further, flow cytometry analysis confirmed absence of endothelial and hematopoietic markers (CD31, CD45) and presence of mesenchymal markers (CD44, CD73, CD90 and CD105) and among cell isolates (Fig. 6C, Supplementary Fig. S9). In addition, all isolated osteosarcoma 
cells underwent both osteogenic and chondrogenic differentiation (Fig. 6D). Basal expression of NELL1 was observed across all HuOS cells (Fig. 6E). Gene deletion studies were then performed among patient-derived OS cells using CRISPR/Cas9. Knockout was confirmed using qRT-PCR (Fig. 6F, 88.1\% reduction). In comparison to vector control, multiple cellular effects were observed among HuOS, including reduced proliferation (Fig. 6G. 46.3\% reduction at $72 \mathrm{~h}$ ), attachment (Fig. 6H. 34.9\% and 24.7\% reduction at 3 and 5 h, respectively), invasion (Fig. 6I, $47.2 \%$ reduction at $24 \mathrm{~h}$ ), and tumorsphere formation (Fig. 6J, 69.7\% reduction at $5 \mathrm{~d}$ ).

Two existing datasets were used to first examine whether high expression of NELL1 serves as a prognostic marker in OS (Fig. 6K, L). Among a mixed population of 73 cases of high grade osteosarcoma, high NELL1 transcripts were associated with a reduced overall survival (Fig. 6K, median overall survival of 34 months in NELL1 ${ }^{\text {high }}$ versus 60 months in NELL1 ${ }^{\text {low }}$ cohort). Analyses performed in 259 cases of high grade sarcomas of soft tissue and bone showed similarly that transcripts of $N E L L 1, F N 1$, or $L A M B 1$ were all associated with decreased overall survival (Fig. 6L, median overall survival of 49, 23, and 54 months in NELL1 ${ }^{\text {high }}$ versus 86, 38, and 90 months in NELL1 ${ }^{\text {low }}$ cohort, respectively). Finally, 5 biopsies of conventional osteosarcoma prior to adjuvant chemotherapy were assessed for the expression of NELL1 and fibronectin (Fig. 6M, N, Supplementary Table S11). Results demonstrated immunoreactivity for both NELL1 and FN1 across all samples, a high degree of co-localization between antigens within biopsy tissue, and a relative correlation between the degree of NELL1 and FN1 immunostaining across samples ((Fig. 6M, N). Collectively, NELL1 is an OS related protein essential for sarcoma cell function via regulation of cell-matrix interactions, and represents a poor prognostic indicator across human sarcomas. 


\section{Discussion}

In this study, we demonstrated that the sarcoma associated protein NELL1 plays an integral role in positively regulating both sarcomagenesis as well as features of aggressive sarcoma behavior on cellular and tumoral levels. In part, this is explained by a modulation of the sarcomatous ECM, which in turn modulates cell-ECM interaction and FAK/Src signaling activation.

The sarcomatous ECM displays distinct histologic, proteomic, and biomechanical properties ${ }^{42,}$ 43, 44, 45 . In some instances, sarcomatous ECM proteins have been linked to metastasis ${ }^{44}$, subsequent growth of metastatic foci ${ }^{43}$, or chemo-resistance ${ }^{15,19,42}$. Bone and soft tissue sarcomas are exceptionally diverse ${ }^{46,47}$, and even within osteosarcoma the matrix components may vary widely in composition ${ }^{15,16}$. Nevertheless, NELL1 expression appears to be present across the histologic spectrum of human osteosarcoma ${ }^{31}$. Prior observations have found NELL1 to be a key protein in the regulation of matrix components during morphogenesis, regeneration and tissue engineering. For example, mice globally deficient in Nell1 have altered ECM protein expression with associated with skeletal developmental anomalies ${ }^{30,48}$. In the context of tissue engineering and regeneration, Qi et al showed recombinant NELL1 treatment induces expression of the structural matrix protein Type II Collagen and promotes the differentiation of chondrocytes ${ }^{48}$. In other contexts, NELL1 enhances the production of the molecule dentin matrix protein 1 (DMP1) accompanied by induction of odontoblastic differentiation ${ }^{49}$. Our study observed similarly striking regulation of sarcoma associated matrix proteins by NELL1, which among other findings altered FAK signaling activity and modulated sarcoma cell functional characteristics. 
An important consideration toward the positive regulatory roles of NELL1 signaling in sarcoma disease progression is the promotion of angiogenesis. In tissue engineering contexts, NELL1 is known to promote angiogenesis during non-neoplastic bone formation through induction of VEGFA expression ${ }^{32,33}$. Here, NELL1 gene deletion led to a down-regulation of VEGF signaling in sarcoma cells, and potent reduction in sarcoma-associated blood vessels. Indeed, VEGF expression correlates with prognosis in patients with sarcoma ${ }^{50}$. Beyond changes in angiogenic factors, it is likely that altered ECM associated with NELL1 KO may also have predisposed to lack of vascular ingrowth. NELL1 deficient sarcoma cells displayed changes in genes and proteins associated with ECM remodeling, including a significant downregulation in MMP9. Matrix metalloproteases (MMPs) are defined by their role in matrix degradation but also in their secondary stimulation of tumor vasculature ${ }^{51}$. For instance, MMP9 renders normal islets into angiogenic islets by mobilizing VEGF during pancreatic carcinogenesis ${ }^{52}$. Thus, changes in sarcoma-associated angiogenesis could be a result of combinatorial factors including NELL1 signaling induced transcription of angiogenic factors as well as altered ECM remodeling.

NELL1 is by no means solely expressed by osteosarcoma. Here, we observed NELL1 expression to serve as a prognostic biomarker among high grade sarcomas of bone (osteosarcoma and Ewings sarcoma), or even mixed diagnostic population of high grade sarcomas of bone and soft tissue. This is consistent with a prior study which implicated NELL1 in migration and invasion of rhabdomyosarcoma (RMS) cells, and negatively correlated NELL1 expression with RMS prognosis ${ }^{53}$. Interestingly, a clear divide seems to be present in the literature between the potential roles of NELL1 in epithelial versus mesenchymal malignant tumors. For example, a GWAS study of non-small cell lung cancer (NSCLC) identified NELL1 
as a tumor suppressor gene ${ }^{54}$. The protective role of NELL1 was confirmed by functional studies conducted in colon cancer, renal cell carcinoma, lung cancer and esophageal adenocarcinoma cell lines and models $55,56,57,58$. Among the numerous differences between carcinomas and sarcomas, our study suggests that the matrix itself may be an important distinguishing factor. Sarcoma cells are often loosely and often haphazardly arranged their sarcomatous ECM ${ }^{59}$, while epithelial cancer cells are closely interacting cells often adherent to one another, but by and large without mesenchymal matrix production. These key cytologic and histologic features serve as future catalysts toward the understanding of the matrix regulating protein NELL1 as a differential disease modifier in carcinoma and sarcoma.

In combination, our aggregate data suggest that NELL1 is a novel protein highly expressed among human osteosarcoma which positively regulates multiple aspects of OS disease progression. Use of gene editing technology, or alternatively small molecule-mediated disruption of NELL1 signaling, may represent an adjunctive tool to improve survival in osteosarcoma and other sarcoma subtypes. 


\section{Materials and Methods}

\section{Mice}

All animal experiments were performed according to approved protocols (MO21M112) of the Animal Care and Use Committee (ACUC) at Johns Hopkins University (JHU). NOD scid mice (Stock No: 001303) were purchased from The Jackson Laboratory (Bar Harbor, ME, USA). OCCre animals were a kind gift from the Clemens laboratory at JHU (JAX Stock No. 019509). $p 53^{\mathrm{fl} / \mathrm{fl}} ; R b^{\mathrm{fl} / \mathrm{fl}}$ mice were a kind gift from the Jones laboratory at University of Utah (JAX Stock No. 008462 and 026563$)$. Nell $1^{\mathrm{fl} / \mathrm{fl}}$ mice were supplied by the Ting/Zhang laboratories at UCLA ${ }^{48}$. In order to achieve spontaneous osteosarcoma formation, $p 53^{\mathrm{fl} / \mathrm{fl}} ; R b^{\mathrm{fl} / \mathrm{fl}}$ (control) mice or $p 53^{\mathrm{fl} / \mathrm{fl}} ; R b^{\mathrm{fl} / \mathrm{fl}} ; N e l l 1^{\mathrm{fl} / \mathrm{fl}}\left(N e l l 1^{\mathrm{OC}} \mathrm{cKO}\right)$ mice were crossbred with OC-Cre animals. Rates of OS tumor formation within $p 53^{\mathrm{fl} / \mathrm{fl}} ; R b^{\mathrm{fl} / \mathrm{fl} l}$;OC-Cre animals were in line with prior reports ${ }^{37}$. Analyses were performed by investigators blinded to the mouse genotype.

\section{Cell isolation, culture and characterization}

Human osteosarcoma cell lines were purchased from American Type Culture Collection (Manassas, VA), including 143B (ATCC®-CRL-8303 ${ }^{\mathrm{TM}}$ ), Saos-2 (ATCC ${ }^{\circledR} \mathrm{HTB}^{\mathrm{B}}-85^{\mathrm{TM}}$ ), HOS

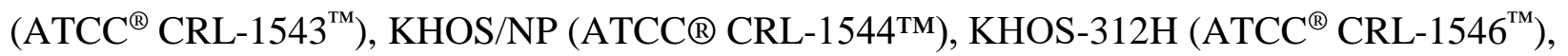
and G-292 (ATCC® CRL-1423 ${ }^{\mathrm{TM}}$ ). Primary human OS cells were derived from human OS resection samples $(n=4)$ under IRB approval at JHU with a waiver of informed consent. The pathologic diagnosis of high grade conventional osteosarcoma was confirmed by two independent bone pathologists (E.F.M. and A.W.J.). Immediately following resection, specimens of human OS were collected under sterile conditions, washed in PBS and dissected into small fragments $\left(<1 \mathrm{~mm}^{3}\right)$. Primary OS tumor cells were derived as per previous descriptions ${ }^{60}$, and 
culture expanded for 3 to 5 passages before use. Characterization of primary tumor cells was performed by flow cytometry, in vitro differentiation and cytogenetic analyses. Karyotyping was performed by the Division of Molecular Pathology at JHU clinical laboratories. Human primary OS cells at passage 3-5 were used for characterization by flow cytometry ${ }^{61}$, including mesenchymal (CD44, CD73, CD90, CD105), endothelial (CD31) and hematopoietic markers (CD45) (see Supplementary Table S12 for all antibody information). Multilineage differentiation of tumor cells was performed for osteogenic and chondrogenic differentiation ${ }^{62}$, with assessments of mineralization at $10 \mathrm{~d}$ and glycosaminoglycan at $14 \mathrm{~d}^{63,64,65}$. Mouse bone marrow mesenchymal stromal cells (BMSCs) were isolated from tibial and femoral bone marrow of either $p 53^{\mathrm{fl} / f \mathrm{l}} ; R b^{\mathrm{fl} / f \mathrm{l}}(\mathrm{DKO})$ or $p 53^{\mathrm{fl} / \mathrm{fl}} ; R b^{\mathrm{fl} / f \mathrm{l} l} ; N e l l 1^{\mathrm{fl} / f \mathrm{l} l}(\mathrm{TKO})$ mice $(\mathrm{n}=4)$ under sterile conditions 66,67. Briefly, bones were dissected from 8-12 week old female mice. Bone marrow was flushed, resuspended in PBS, and filtered through a 70-mm filter. Bone marrow cells were cultured in 10cm culture dishes and incubated at $37{ }^{\circ} \mathrm{C}$ with $5 \% \mathrm{CO} 2$ in a humidified chamber. After $3 \mathrm{~h}$, nonadherent cells were removed. All cells were cultured in Dulbecco's Modified Eagle Medium (DMEM, Gibco, Grand Island, NY) supplemented with 15\% fetal bovine serum (FBS, Gibco), $100 \mathrm{U} / \mathrm{ml}$ penicillin and $100 \mu \mathrm{g} / \mathrm{ml}$ streptomycin (Gibco) in a humidified incubator with $5 \% \mathrm{CO}_{2}$ at $37^{\circ} \mathrm{C}$.

\section{NELL1 gene deletion and isolation of cell clones}

CRISPR/Cas9 gene deletion of NELL1 in human OS cell lines and primary cells was achieved using a plasmid with a guide RNA (gRNA) sequence combined with U6gRNA-Cas9-2A-RFP vector (Sigma-Aldrich). The specific gRNA sequence of knockout and negative control plasmids were as in Supplementary Table S13. The transient plasmid DNA transfection was performed 
using TransIT®-LT1 Transfection Reagent (Mirus, Madisom, WI). Briefly, cells were plated at an initial density of $3 \times 10^{5}$ cells $/ \mathrm{ml}$ in 6 -well cell culture plates and incubated for $24 \mathrm{~h}$. Cells were then transfected with TransIT-LT1 Reagent-plasmid DNA complex containing $250 \mu 1$ of OptiMEM Reduced-Serum Medium (Gibco), $2.5 \mu \mathrm{g}$ plasmid DNA and $7.5 \mu \mathrm{l}$ TransIT-LT1 Reagent and incubated for $72 \mathrm{~h}$. Next, NELL1 KO single cell colonies were established by FACS. Viable RFP-positive cells from NELL1 KO-transfected cells and control-transfected cells were sorted into wells of a 96-well microtiter plate by using a Dako Cytomation MoFlo cell-sorter (Beckman, Indianapolis, IN). For single cell deposition, cells were sorted using the 70-mm nozzle with the sheath pressure set at 70 PSI using the sort precision mode set at single cell. After confirmation of gene deletion by qRT-PCR, $n=6$ colonies were expanded for use. Finally, to achieve Nell1 gene deletion of in murine cells, BMSCs derived from either $p 53^{\mathrm{fl} / \mathrm{fl}} ; R b^{\mathrm{fl} / \mathrm{fl}}$ $(\mathrm{DKO})$ or $p 53^{\mathrm{fl} / \mathrm{fl}} ; R b^{\mathrm{fl} / \mathrm{fl}} ; N e l l 1^{\mathrm{fl} / f \mathrm{l} l}(\mathrm{TKO})$ mice and were treated with either Ad-GFP-2A-iCre (Vector Biolabs, Cat No. 1772) or Ad-CMV-GFP (Vector Biolabs, Cat No. 1060) at 200 MOI.

\section{T7 Endonuclease I Assay}

NELL1 KO and control-transfected cells were collected for the detection of the mutation using the T7 Endonuclease I Assay Kit (Genocopoeis, Rockville, MD). DNA was extracted from the samples using Quick-DNA ${ }^{\text {TM }}$ Miniprep Kit (Zymo Research, Irvine, CA). See Supplementary Table S13 for primer information. The PCR reactions were performed according to the manufacturer's protocol. The PCR product was then digested using T7E1 enzyme at $37^{\circ} \mathrm{C}$ for 60 min, followed by separation using $1.5 \%$ agarose gel electrophoresis.

\section{In vitro functional assays}


Firstly, cell proliferation was assessed using the CellTiter 96® AQueous Non-Radioactive MTS Cell Proliferation Assay (Promega, Madison, WI) ${ }^{62,68} .2 \times 10^{3}$ cells were plated in 96-well plates and incubated for 24,48 , and $72 \mathrm{~h}$. The optical density at $490 \mathrm{~nm}$ was measured on a microplate spectrophotometer (BioTek, Winooski, VT). Second, cell attachment was measured by crystal violet staining ${ }^{69} .2 \times 10^{5}$ cells were plated in 24 -well plates and incubated for 1,3 and 5 h. Cells were washed with cold PBS and fixed with $100 \%$ methanol, then stained with $0.5 \%$ crystal violet solution for $10 \mathrm{~min}$ at RT. Stained cells were lysed in $10 \%$ acetic acid and absorbance was measured at $570 \mathrm{~nm}$. In select experiments, Nell1 signaling was rescued by adenoviral NELL1 (Ad-NELL1) or control (Ad-LacZ). In select experiments, tissue culture plates were pre-coated with $5 \mu \mathrm{g} / \mathrm{cm}^{2}$ of either Fibronectin (Sigma-Millipore) or Laminin (Sigma-Millipore). Thirdly, migration assays were carried out using the Culture-Insert 2 Well (Ibidi, Martinsried, Germany) ${ }^{63} .4 \times 10^{4}$ cells were added into each well and incubated overnight. Next, the insert wells were gently removed and the plate replenished with growth medium. The cells were incubated for 12 and $24 \mathrm{~h}$ and photographs were taken under an inverted microscope (Olympus, Tokyo, Japan). The width of the cell-free gap was measured by using ImageJ software (Version $1.49 \mathrm{v}, \mathrm{NIH}$, Bethesda, MD).

Fourth, invasion assays were carried out using Corning ${ }^{\circledR}$ BioCoat ${ }^{\mathrm{TM}}$ Matrigel ${ }^{\circledR}$ Invasion Chambers (Corning, Bedford, MA). Briefly, $2.5 \times 10^{5}$ cells in serum-free medium were added to the upper chamber, while $500 \mu \mathrm{l}$ growth medium was added to the lower chamber. After $24 \mathrm{~h}$ incubation, cells were fixed with cold $100 \%$ methanol and stained with $0.5 \%$ crystal violet solution. Photographs of five random regions were taken under an inverted microscope (Olympus) and the number of invaded cells was enumerated. Fifth, tumorsphere assays were 
performed using primary OS cells with or without NELL1 KO which were trypsinized to generate a single cell suspension and seeded into 6-well ultralow attachment plates (Corning) at a density of $5 \times 10^{5}$ cells, followed by culturing in defined sphere medium ${ }^{70,71}$. Spheres were imaged on day 7 using an inverted microscope (Olympus) and the number of spheres were manually counted.

\section{$q R T-P C R$}

Total RNA was extracted from cultured cells of equal passage number and density using TRIzol Reagent (Invitrogen, Carlsbad, CA) according to the manufacturer's instructions. $1 \mu \mathrm{g}$ of total RNA was used for reverse transcription with iScript cDNA synthesis kit (Bio-Rad). Real-time PCR was performed using SYBR Green PCR Master Mix (Thermo Scientific, Waltham, MA). Relative gene expression was calculated using a $2^{-\Delta \Delta C t}$ method by normalization with GAPDH. The primer sequences were listed in Supplemental Table S13.

\section{Western blot}

Cells were lysed in RIPA buffer (Thermo Scientific) with protease inhibitor cocktail (Cell Signaling Technology, Danvers, MA, USA). Proteins concentration were determined by BCA assay (Thermo Scientific). Cell lysates were separated by SDS-polyacrylamide gel electrophoresis and transferred onto a nitrocellulose membrane. Protein extraction was blocked with $5 \%$ bovine serum albumin and incubated with primary antibodies at $4^{\circ} \mathrm{C}$ overnight. Finally, membranes were incubated with a horseradish-peroxidase (HRP)-conjugated secondary antibody and detected with ChemiDoc XRS+ System (Bio-rad). The antibodies were listed in

\section{Supplemental Table S12.}




\section{Total RNA Sequencing}

Gene expression was detected by total RNA sequencing using the Illumina NextSeq 500 platform (Illumina, San Diego, CA). Briefly, total RNA was extract from clonal 143B cells with or without NELL1 KO by Trizol (Life Technologies Corporation, Gaithersburg, MD). The total RNA samples were sent to the JHMI Deep Sequencing and Microarray core (JHU) for sequencing. Data analysis were performed using software packages including CLC Genomics Server and Workbench (RRID:SCR_017396 and RRID:SCR_011853), Partek Genomics Suite (RRID:SCR_011860), Spotfire DecisopnSite with Functional Genomics (RRID:SCR_008858), and QIAGEN Ingenuity Pathway Analysis (RRID:SCR_008653).

\section{Reverse phase protein analysis}

Protein lysates were isolated from control and NELL1 KO clonal 143B cells (4 biological replicates). Modified RIPA buffer containing proteinase and phosphatase inhibitor was used for the lysis. Cellular proteins were denatured by $1 \%$ SDS with $\beta$-mercaptoethanol and analyzed by the Reverse Phase Protein Array (RPPA) Core at MD Anderson Cancer Center (https://www.mdanderson.org/research/research-resources/core-facilities/functional-proteomicsrppa-core.html). Briefly, protein lysates were diluted in five two-fold serial dilutions (undiluted, 1:2, 1:4, 1:8; 1:16) and arrayed on nitrocellulose-coated slides (Grace Bio Lab). Each slide was probed with a validated primary antibody plus a biotin-conjugated secondary antibody. The RPPA slides for 453 unique antibodies were scanned, analyzed, and quantified using a customized-software to generate spot intensity. Relative protein levels for each sample were determined by interpolating each dilution curve produced from the densities of the 5-dilution 
sample spots using a standard curve for each antibody. Relative protein levels are designated as $\log 2$ values. The protein concentrations of each set of slides were then normalized for protein loading 72,73 .

\section{Osteosarcoma implantation and assessments}

All animal studies were performed with institutional ACUC approval within Johns Hopkins University, complying with all relevant ethical regulations. Experimental details and animal numbers are also summarized in Supplementary Table S14. For all 143B OS cell implantation, 8-10 week old, male and female, NOD scid mice were used. $1 \times 10^{6}$ clonal 143B cells with or without NELL1 KO in $50 \mu \mathrm{PBS}$ were injected subperiosteally within the proximal tibia metaphysis. Tumor size was measured by caliper twice weekly for 4 wks, and tumor volume was calculated ${ }^{74}$. Experiments were replicated with a second cell clone. Magnetic resonance imaging (MRI) was performed as previously described ${ }^{75}$ at 14 and $28 \mathrm{~d}$ post injection, and tumor size was calculated using ImageJ. Primary tumors and lungs were harvested at $28 \mathrm{~d}$ postinjection for histologic analysis. In a separate study, overall survival was evaluated from the first day of tumor cell injection until death using the Kaplan-Meier estimate. In a separate study, 143B cells with or without NELL1 knockout were injected systemically by tail vein $\left(1.5 \times 10^{6}\right.$ clonal 143B cells in $100 \mu \mathrm{l}$ PBS). Mice were monitored three time weekly and sacrificed $28 \mathrm{~d}$ after injection for assessment of pulmonary burden of disease. In a separate study, $1 \times 10^{6}$ murine BMSCs in $50 \mu \mathrm{l}$ PBS $\left(p 53^{\mathrm{fl} / \mathrm{fl}} ; R b^{\mathrm{fl} / \mathrm{fl}}\right.$ or $p 53^{\mathrm{fl} / \mathrm{fl}} ; R b^{\mathrm{fl} / \mathrm{fl}} ; N e l l 1^{\mathrm{fl} / \mathrm{fl}}$ genotypes $2 \mathrm{~d}$ after Ad-Cre mediated transformation) were injected subperiosteally within the proximal tibia metaphysis. Tumor formation was monitored three times weekly and tumor free survival was recorded. 
Samples were harvested $28 \mathrm{~d}$ after tumor formation was observed. Analyses were performed by investigators blinded to the tumor type.

\section{Spontaneous osteosarcomagenesis and assessments}

The spontaneous osteosarcoma mice model is based on osteoblast-restricted deletion of p53 and $\mathrm{pRb}^{35,36}$. Either $p 53^{\mathrm{fl} / f 1} ; R b^{\mathrm{fl} / \mathrm{fl}}$ mice or $p 53^{\mathrm{fl} / \mathrm{fl}} ; R b^{\mathrm{fl} / f 1} ; N e l l 1^{\mathrm{fl} / f \mathrm{l} l}$ mice were crossed with $p 53^{\mathrm{fl} /+} ; R b^{\mathrm{fl} /++} ; \mathrm{OC}-C r e$ mice or $p 53^{\mathrm{fl} /++} ; R b^{\mathrm{fl} /+} ; N e l l 1^{\mathrm{fl} /+} ;$ OC-Cre mice, respectively. The offspring with genotype of $p 53^{\mathrm{fl} / \mathrm{fl}} ; R b^{\mathrm{fl} / f \mathrm{fl}} ;$ OC-Cre (control) and $p 53^{\mathrm{fl} / f \mathrm{l} l} ; R b^{\mathrm{fl} / \mathrm{fl}} ; N e l l 1^{\mathrm{fl} / / \mathrm{fl}} ; \mathrm{OC}-\mathrm{Cre}\left(N e l l 1^{\mathrm{OC}}\right.$ cKO) were used in this study. Tumor formation was monitored three times weekly and tumor free survival was recorded. Tumors were harvested $28 \mathrm{~d}$ after tumor formation was observed. Analyses were performed by investigators blinded to the mouse genotype.

\section{Histology and Immunohistochemistry}

Primary tumor samples and lungs were fixed in $4 \%$ paraformaldehyde (PFA) at $4{ }^{\circ} \mathrm{C}$ for $24 \mathrm{~h}$ and decalcified in $14 \%$ EDTA (Sigma-Aldrich) for up to $56 \mathrm{~d}$ at $4^{\circ} \mathrm{C}$. Samples were then cryoprotected in $30 \%$ sucrose overnight at $4^{\circ} \mathrm{C}$ and embedded in optimal cutting temperature compound (OCT, Tissue-Tek 4583, Torrance, CA) for cryosectioning at $10 \mu \mathrm{m}$ thickness. Routine H\&E staining was performed on the entire lung tissues sectioned in a coronal plane to assess pulmonary burden, and number of metastasis foci were manually counted. For immunohistochemistry, sagittal sections of primary or metastatic tumors were washed in PBS $\times$ 3 for 10 min and permeabilized with $0.5 \%$ Triton-X for 30 min. Next, 5\% normal goat serum (S1000, Vector Laboratories, Burlingame, CA) was applied for $30 \mathrm{~min}$, then incubated in primary antibodies overnight at $4^{\circ} \mathrm{C}$. The following day, slides were washed in PBS, incubated in the 
secondary antibody for $1 \mathrm{~h}$ at $25^{\circ} \mathrm{C}$, and then mounted with DAPI mounting solution (Vectashield H-1500, Vector Laboratories). Digital images of these sections were captured with 10-100 × objectives using upright fluorescent microscopy (Leica DM6, Leica Microsystems Inc., Buffalo Grove, IL). Analyses were performed by investigators blinded to the sample identification.

\section{Statistical analysis}

Results are expressed as the mean \pm 1 SD. A Shapiro-Wilk test for normality was performed on all datasets. Homogeneity was confirmed by a comparison of variances test. Parametric data was analyzed using either a Student's t test for a two group comparison, or one-way analysis of variance when more than two groups were compared, followed by a post hoc Tukey test (Graphpad Software 7.0). $* P<0.05$ and $* * P<0.01$ were considered significant. For in vivo $143 \mathrm{~B}$ implantation studies, the sample size was calculated based on an anticipated effect size of 2.0 based on our in vitro studies comparing NELL1 KO and vector control. For this scenario, with eight replicates per group will provide $80 \%$ power to detect effect sizes of at least 1.5 , assuming a two-sided 0.05 level of significance. 


\section{Acknowledgments}

Support to AWJ is provided by American Cancer Society (Research Scholar Grant, RSG-18027-01-CSM), NIH/NIAMS (R01 AR070773, R01 AR079171), Department of Defense (USAMRAA W81XWH-18-1-0336, W81XWH-18-1-0121, W81XWH-20-1-0795, W81XWH20-1-0302), and the Maryland Stem Cell Research Foundation. The content is solely the responsibility of the authors and does not necessarily represent the official views of the National Institute of Health or Department of Defense. We thank the JHU microscopy core facility, JHMI deep sequencing and microarray core facility, division of molecular pathology and Hao Zhang within the JHU Bloomberg Flow Cytometry and Immunology Core. 


\section{Author contributions}

Conception and design: Q.Q., A.W.J.; funding and final manuscript approval: A.W.J.; acquisition, analysis, and interpretation of data: Q.Q., M.G.S., R.J.T., L.C., K.T., and X.Z.; donation of clinical samples: C.D.M., and E.F.M.; manuscript preparation: Q.Q., and A.W.J. 


\section{Conflict of interest}

A.W.J. is a paid consultant for Novadip and Lifesprout LLC. This arrangement has been reviewed and approved by the Johns Hopkins University in accordance with its conflict of interest policies. 


\section{Supplementary Materials}

Fig. S1. Validation of CRISPR-Cas9 mediated NELL1 KO efficiency.

Fig. S2. CRISPR-Cas9 mediated NELL1 KO in polyclonal 143B cells.

Fig. S3. NELL1 gene deletion mitigates OS disease progression.

Fig. S4. Cellular behavior after adenovirus-mediated p53/Rb gene deletion in mouse BMSCs.

Fig. S5. Additional transcriptomic analysis of clonal 143B cells with or without NELL1 gene deletion.

Fig. S6. Additional proteomic analysis of clonal 143B cells with or without NELL1 gene deletion.

Fig. S7. Full-size blots of Figure 5I.

Fig. S8. Representative flow cytometry of primary OS cells used in Figure 6C.

Supplementary Table S1. Tumor penetrance for mouse cell implantation model.

Supplementary Table S2. Summary of tumor formation within spontaneous OS mouse model with or without Nell1 gene deletion.

Supplementary Table S3. Summary of spontaneous OS tumors location and incidence.

Supplementary Table S4. Most downregulated pathways among NELL1 KO clonal 143B cells by Ingenuity Pathway Analysis.

Supplementary Table S5. Most upregulated pathways among NELL1 KO clonal 143B cells by Ingenuity Pathway Analysis.

Supplementary Table S6. Osteosarcoma related genes in clonal 143B cells (NELL1 KO vs. Vector control).

Supplementary Table S7. Most downregulated Gene Ontology terms among NELL1 KO clonal 143B cells by RNA sequencing. 
Supplementary Table S8. Most upregulated Gene Ontology terms among NELL1 KO clonal 143B cells by RNA sequencing.

Supplementary Table S9: Most downregulated Gene Ontology terms among NELL1 KO clonal 143B cells by proteomic analysis.

Supplementary Table S10. Most upregulated Gene Ontology terms among NELL1 KO clonal 143B cells by proteomic analysis.

Supplementary Table S11. Summary of NELL1 and FN1 immunostaining in biopsy samples of high grade conventional osteosarcoma.

Supplementary Table S12. Antibodies used.

Supplementary Table S13. CRISPR/Cas9 sgRNA and primer sequences.

Supplementary Table S14. Summary of osteosarcoma cell implantation models. 


\section{References}

1. Dancsok AR, Asleh-Aburaya K, Nielsen TO. Advances in sarcoma diagnostics and treatment. Oncotarget 8, 7068-7093 (2017).

2. van der Laan P, van Houdt WJ, van den Broek D, Steeghs N, van der Graaf WTA. Liquid Biopsies in Sarcoma Clinical Practice: Where Do We Stand? Biomedicines 9, (2021).

3. Lewis DM, et al. A Feedback Loop between Hypoxia and Matrix Stress Relaxation Increases Oxygen-Axis Migration and Metastasis in Sarcoma. Cancer Res 79, 1981-1995 (2019).

4. Frantz C, Stewart KM, Weaver VM. The extracellular matrix at a glance. J Cell Sci 123, 4195-4200 (2010).

5. Multhaupt HA, Leitinger B, Gullberg D, Couchman JR. Extracellular matrix component signaling in cancer. Adv Drug Deliv Rev 97, 28-40 (2016).

6. Levental KR, et al. Matrix crosslinking forces tumor progression by enhancing integrin signaling. Cell 139, 891-906 (2009).

7. Yuan Y, Shen N, Yang SY, Zhao L, Guan YM. Extracellular matrix metalloproteinase inducer and matrix metalloproteinase-2 overexpression is associated with loss of hormone receptor expression and poor prognosis in endometrial cancer. Oncol Lett 10, 342-348 (2015). 
8. Ivanov V, Ivanova S, Roomi MW, Kalinovsky T, Niedzwiecki A, Rath M. Naturally produced extracellular matrix inhibits growth rate and invasiveness of human osteosarcoma cancer cells. Med Oncol 24, 209-217 (2007).

9. Scarpa S, Modesti A, Triche TJ. Extracellular matrix synthesis by undifferentiated childhood tumor cell lines. Am J Pathol 129, 74-85 (1987).

10. Brosicke N, Sallouh M, Prior LM, Job A, Weberskirch R, Faissner A. Extracellular Matrix Glycoprotein-Derived Synthetic Peptides Differentially Modulate Glioma and Sarcoma Cell Migration. Cell Mol Neurobiol 35, 741-753 (2015).

11. Anderson ME. Update on Survival in Osteosarcoma. Orthop Clin North Am 47, 283-292 (2016).

12. Qiu S, Tao L, Zhu Y. Marital Status and Survival in Osteosarcoma Patients: An Analysis of the Surveillance, Epidemiology, and End Results (SEER) Database. Med Sci Monit 25, 8190-8203 (2019).

13. Song K, et al. Survival analysis of patients with metastatic osteosarcoma: a Surveillance, Epidemiology, and End Results population-based study. Int Orthop 43, 1983-1991 (2019). 
14. Amankwah EK, Conley AP, Reed DR. Epidemiology and therapies for metastatic sarcoma. Clin Epidemiol 5, 147-162 (2013).

15. Cui J, Dean D, Hornicek FJ, Chen Z, Duan Z. The role of extracelluar matrix in osteosarcoma progression and metastasis. J Exp Clin Cancer Res 39, 178 (2020).

16. Nikitovic D, et al. Parathyroid hormone/parathyroid hormone-related peptide regulate osteosarcoma cell functions: Focus on the extracellular matrix (Review). Oncol Rep 36, 1787-1792 (2016).

17. Na KY, Bacchini P, Bertoni F, Kim YW, Park YK. Syndecan-4 and fibronectin in osteosarcoma. Pathology 44, 325-330 (2012).

18. Shi K, Wang SL, Shen B, Yu FQ, Weng DF, Lin JH. Clinicopathological and prognostic values of fibronectin and integrin alphavbeta3 expression in primary osteosarcoma. World J Surg Oncol 17, 23 (2019).

19. Xiao Z, et al. Targeting CD44 by CRISPR-Cas9 in Multi-Drug Resistant Osteosarcoma Cells. Cell Physiol Biochem 51, 1879-1893 (2018).

20. De Vita A, et al. The potential role of the extracellular matrix in the activity of trabectedin in UPS and L-sarcoma: evidences from a patient-derived primary culture case series in tridimensional and zebrafish models. J Exp Clin Cancer Res 40, 165 (2021). 
21. Li C, Zhang X, Zheng Z, Nguyen A, Ting K, Soo C. Nell-1 Is a Key Functional Modulator in Osteochondrogenesis and Beyond. J Dent Res 98, 1458-1468 (2019).

22. Tanjaya J, et al. The Effects of Systemic Therapy of PEGylated NEL-Like Protein 1 (NELL-1) on Fracture Healing in Mice. Am J Pathol 188, 715-727 (2018).

23. Shen J, et al. Novel Wnt Regulator NEL-Like Molecule-1 Antagonizes Adipogenesis and Augments Osteogenesis Induced by Bone Morphogenetic Protein 2. Am J Pathol 186, 419-434 (2016).

24. Lee S, et al. Brief Report: Human Perivascular Stem Cells and Nel-Like Protein-1 Synergistically Enhance Spinal Fusion in Osteoporotic Rats. Stem Cells 33, 3158-3163 (2015).

25. James AW, et al. NELL-1 in the treatment of osteoporotic bone loss. Nat Commun 6 , $7362(2015)$.

26. Kwak J, et al. NELL-1 injection maintains long-bone quantity and quality in an ovariectomy-induced osteoporotic senile rat model. Tissue Eng Part A 19, 426-436 (2013). 
27. Ting K, et al. Human NELL-1 expressed in unilateral coronal synostosis. J Bone Miner Res 14, 80-89 (1999).

28. Li W, et al. Nell-1 enhances bone regeneration in a rat critical-sized femoral segmental defect model. Plast Reconstr Surg 127, 580-587 (2011).

29. James AW, et al. Vertebral Implantation of NELL-1 Enhances Bone Formation in an Osteoporotic Sheep Model. Tissue Eng Part A 22, 840-849 (2016).

30. Desai J, et al. Nell1-deficient mice have reduced expression of extracellular matrix proteins causing cranial and vertebral defects. Hum Mol Genet 15, 1329-1341 (2006).

31. Shen J, et al. NELL-1 expression in benign and malignant bone tumors. Biochem Biophys Res Commun 460, 368-374 (2015).

32. Fahmy-Garcia S, et al. NELL-1, HMGB1, and CCN2 Enhance Migration and Vasculogenesis, But Not Osteogenic Differentiation Compared to BMP2. Tissue Eng Pt A 24, 207-218 (2018).

33. Zhang X, et al. The Nell-1 growth factor stimulates bone formation by purified human perivascular cells. Tissue Eng Part A 17, 2497-2509 (2011). 
34. Askarinam A, et al. Human Perivascular Stem Cells Show Enhanced Osteogenesis and Vasculogenesis with Nel-Like Molecule I Protein. Tissue Eng Pt A 19, 1386-1397 (2013).

35. Walkley CR, et al. Conditional mouse osteosarcoma, dependent on p53 loss and potentiated by loss of Rb, mimics the human disease. Genes Dev 22, 1662-1676 (2008).

36. Berman SD, et al. Metastatic osteosarcoma induced by inactivation of $\mathrm{Rb}$ and $\mathrm{p} 53$ in the osteoblast lineage. Proc Natl Acad Sci U S A 105, 11851-11856 (2008).

37. Quist T, Jin H, Zhu JF, Smith-Fry K, Capecchi MR, Jones KB. The impact of osteoblastic differentiation on osteosarcomagenesis in the mouse. Oncogene 34, 42784284 (2015).

38. Bilbao-Aldaiturriaga N, et al. A systematic review and meta-analysis of MDM2 polymorphisms in osteosarcoma susceptibility. Pediatr Res 80, 472-479 (2016).

39. Iwata $\mathrm{S}$, et al. CDK4 overexpression is a predictive biomarker for resistance to conventional chemotherapy in patients with osteosarcoma. Oncology Reports 46, (2021).

40. Gao Y, et al. CD44 is a direct target of miR-199a-3p and contributes to aggressive progression in osteosarcoma. Sci Rep-Uk 5, (2015). 
41. Shen J, et al. BMP2-Induced Inflammation Can Be Suppressed by the Osteoinductive Growth Factor NELL-1. Tissue Eng Pt A 19, 2390-2401 (2013).

42. Bai C, Yang M, Fan Z, Li S, Gao T, Fang Z. Associations of chemo- and radio-resistant phenotypes with the gap junction, adhesion and extracellular matrix in a threedimensional culture model of soft sarcoma. J Exp Clin Cancer Res 34, 58 (2015).

43. Chen PC, Cheng HC, Yang SF, Lin CW, Tang CH. The CCN family proteins: modulators of bone development and novel targets in bone-associated tumors. Biomed Res Int 2014, 437096 (2014).

44. Hawkins AG, et al. The Ewing Sarcoma Secretome and Its Response to Activation of Wnt/beta-catenin Signaling. Mol Cell Proteomics 17, 901-912 (2018).

45. Saggioro M, D'Angelo E, Bisogno G, Agostini M, Pozzobon M. Carcinoma and Sarcoma Microenvironment at a Glance: Where We Are. Frontiers in Oncology 10, (2020).

46. Kondo T. Current status of proteomics of soft tissue sarcomas. Expert Rev Proteomics 14, 1131-1140 (2017).

47. Ingley KM, et al. Current approaches to management of bone sarcoma in adolescent and young adult patients. Pediatr Blood Cancer, e29442 (2021). 
48. Qi HC, et al. Inactivation of Nell-1 in Chondrocytes Significantly Impedes Appendicular Skeletogenesis. Journal of Bone and Mineral Research 34, 533-546 (2019).

49. Liu M, Wang Q, Tang R, Cao R, Wang X. Nel-like Molecule 1 Contributes to the Odontoblastic Differentiation of Human Dental Pulp Cells. J Endod 42, 95-100 (2016).

50. DuBois S, Demetri G. Markers of angiogenesis and clinical features in patients with sarcoma. Cancer 109, 813-819 (2007).

51. Jacob A, Prekeris R. The regulation of MMP targeting to invadopodia during cancer metastasis. Front Cell Dev Biol 3, 4 (2015).

52. Bergers G, et al. Matrix metalloproteinase-9 triggers the angiogenic switch during carcinogenesis. Nat Cell Biol 2, 737-744 (2000).

53. Tombolan L, et al. NELL1, whose high expression correlates with negative outcomes, has different methylation patterns in alveolar and embryonal rhabdomyosarcoma.

Oncotarget 8, 33086-33099 (2017).

54. Wu XF, et al. Genome-Wide Association Study of Genetic Predictors of Overall Survival for Non-Small Cell Lung Cancer in Never Smokers. Cancer Research 73, 4028-4038 (2013). 
55. Jin Z, et al. Hypermethylation of the nel-like 1 gene is a common and early event and is associated with poor prognosis in early-stage esophageal adenocarcinoma. Oncogene 26, 6332-6340 (2007).

56. Mori Y, et al. A genome-wide search identifies epigenetic silencing of somatostatin, tachykinin-1, and 5 other genes in colon cancer. Gastroenterology 131, 797-808 (2006).

57. Nakamura R, et al. Expression and regulatory effects on cancer cell behavior of NELL1 and NELL2 in human renal cell carcinoma. Cancer Sci 106, 656-664 (2015).

58. Zhai Y, et al. Effect of NELL1 on lung cancer stemlike cell differentiation. Oncol Rep 41, 1817-1826 (2019).

59. Thiery JP, Acloque H, Huang RY, Nieto MA. Epithelial-mesenchymal transitions in development and disease. Cell 139, 871-890 (2009).

60. Maniscalco L, et al. PDGFs and PDGFRs in canine osteosarcoma: new targets for innovative therapeutic strategies in comparative oncology. Vet J 195, 41-47 (2013).

61. Zhang T, Lee YW, Rui YF, Cheng TY, Jiang XH, Li G. Bone marrow-derived mesenchymal stem cells promote growth and angiogenesis of breast and prostate tumors. Stem Cell Res Ther 4, 70 (2013). 
62. $\mathrm{Xu} \mathrm{J}$, et al. Lysosomal protein surface expression discriminates fat- from bone-forming human mesenchymal precursor cells. Elife 9, (2020).

63. $\mathrm{Xu} \mathrm{J}$, et al. Human perivascular stem cell-derived extracellular vesicles mediate bone repair. Elife 8, (2019).

64. Meyers CA, et al. Skeletogenic Capacity of Human Perivascular Stem Cells Obtained Via Magnetic-Activated Cell Sorting. Tissue Eng Part A 25, 1658-1666 (2019).

65. Wang Y, et al. PDGFRalpha marks distinct perivascular populations with different osteogenic potential within adipose tissue. Stem Cells 38, 276-290 (2020).

66. Soleimani M, Nadri S. A protocol for isolation and culture of mesenchymal stem cells from mouse bone marrow. Nature Protocols 4, 102-106 (2009).

67. Huang S, Xu LL, Sun YX, Wu TY, Wang KX, Li G. An improved protocol for isolation and culture of mesenchymal stem cells from mouse bone marrow. J Orthop Transl 3, 2633 (2015).

68. Wang YY, et al. PDGFR alpha marks distinct perivascular populations with different osteogenic potential within adipose tissue. Stem Cells 38, 276-290 (2020). 
69. Shen J, et al. NELL-1 promotes cell adhesion and differentiation via integrin ss 1 . Journal of Cellular Biochemistry 113, 3620-3628 (2012).

70. Fan HJ, et al. ASB13 inhibits breast cancer metastasis through promoting SNAI2 degradation and relieving its transcriptional repression of YAP. Gene Dev 34, 1359-1372 (2020).

71. Chen YY, et al. MAFB Promotes Cancer Stemness and Tumorigenesis in Osteosarcoma through a Sox9-Mediated Positive Feedback Loop. Cancer Research 80, 2472-2483 (2020).

72. Sun C, et al. Rational combination therapy with PARP and MEK inhibitors capitalizes on therapeutic liabilities in RAS mutant cancers. Sci Transl Med 9, (2017).

73. Zhang D, et al. Oncogenic RAS Regulates Long Noncoding RNA Orilnc1 in Human Cancer. Cancer Res 77, 3745-3757 (2017).

74. Niu G, et al. Cetuximab-based immunotherapy and radioimmunotherapy of head and neck squamous cell carcinoma. Clin Cancer Res 16, 2095-2105 (2010).

75. Foroutan P, et al. Diffusion MRI and novel texture analysis in osteosarcoma xenotransplants predicts response to anti-checkpoint therapy. PLoS One 8, e82875 (2013). 


\section{Figures and Legends}

\section{Figure 1.}

A

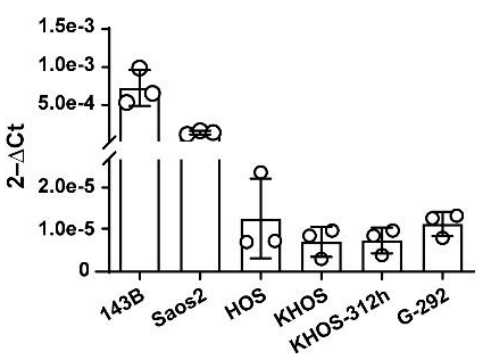

D

$\mathbf{F}$

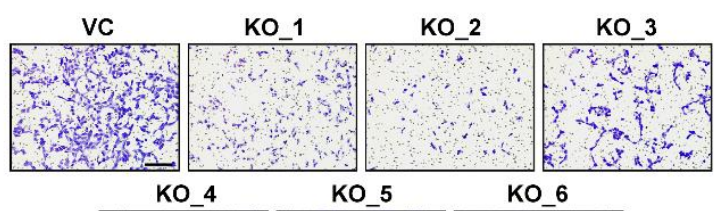

B

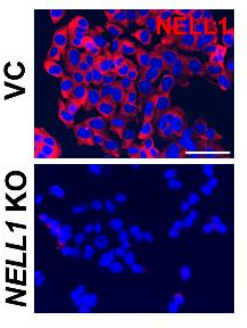

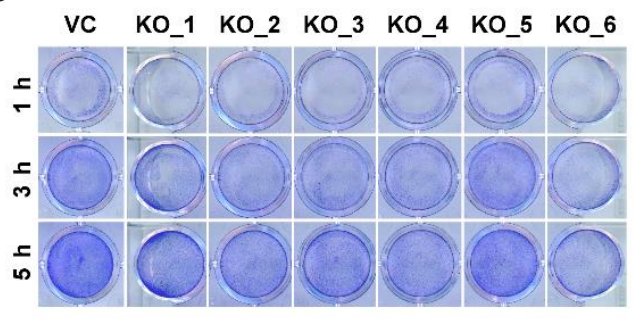

H

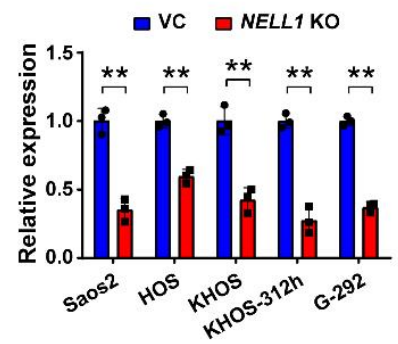

I
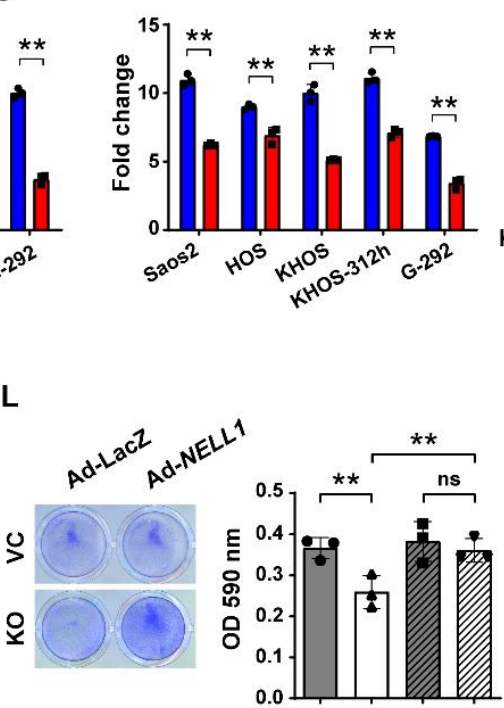

E
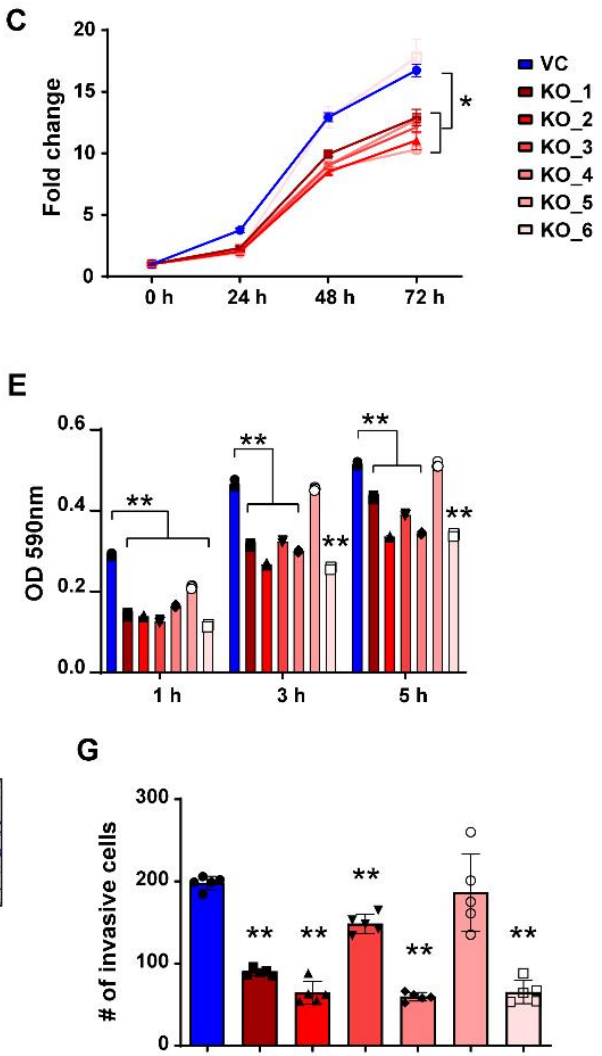

E

G
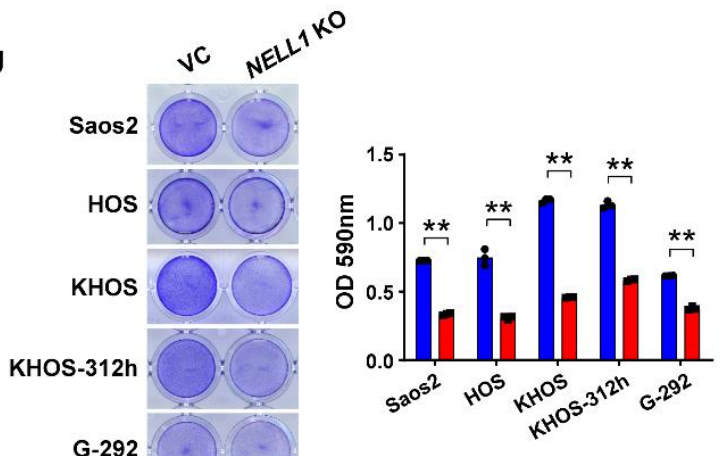

$\mathbf{L}$

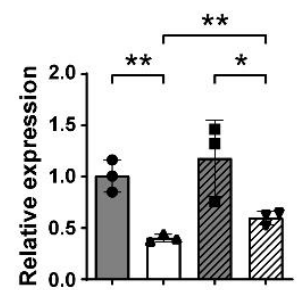

K

$\square \mathrm{VC}+\mathrm{Ad}-\mathrm{LacZ} \square \mathrm{NELL1}$ KO + Ad-LacZ $\square$ VC + Ad-NELL1 $\square \square$ NELL1 KO + Ad-NELL1
M

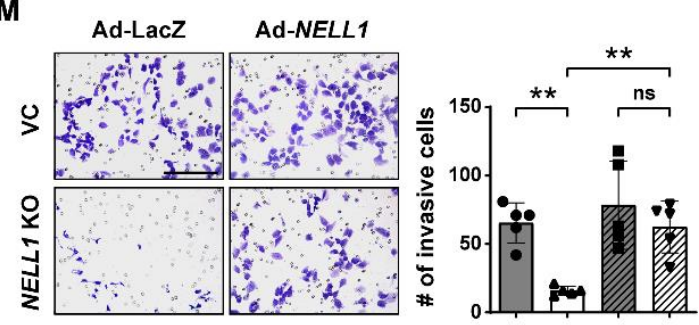




\section{Figure 1. Cell autonomous effects of CRISPR/Cas9-mediated NELL1 gene deletion in}

human osteosarcoma cell lines. (A) NELL1 expression by qRT-PCR in osteosarcoma cell lines. (B-G) Effects of NELL1 gene deletion in 143B cells. (B) Confirmation of NELL1 knockout (KO) in single cell clones by representative immunocytochemical staining, in comparison to vector control (VC). Additional data shown in Supplementary Figure S1. (C) MTS proliferation assay among NELL1 KO single cell clones at 24, 48, and 72 h. (D, E) Attachment assay at 3 and 5 h assessed by (D) crystal violet staining and (E) quantification. (F, G) Transwell invasion assay at $24 \mathrm{~h}$, including (F) representative images and (G) quantification. (H-J) Effects of CRISPR-mediated NELL1 gene deletion across other human OS cell lines, including Saos2, HOS, KHOS, KHOS312h, and G292 cells. (H) Confirmation of NELL1 KO by qRT-PCR. (I) MTS proliferation assay at $72 \mathrm{~h}$. (J) Attachment by crystal violet staining and quantification at 5 h. (K-M) Effects of adenoviral NELL1 (Ad-NELL1) among 143B cells with or without NELL1 gene deletion. Experiments performed in comparison to Ad-LacZ control. (K) NELL1 gene expression by qRT-PCR. (L) Attachment assay by crystal violet staining and quantification at 5 h. (M) Transwell invasion assay and quantification at $24 \mathrm{~h}$. Data shown as mean $\pm 1 \mathrm{SD}$, with dots representing individual datapoints. All experiments performed in triplicate replicates, with results from a single replicate shown. ${ }^{*} P<0.05$; $* * P<0.01$; ns: non-significant. Scale bars: 500 $\mu \mathrm{m}$. A two-tail Student's $t$ test was used for two group comparisons (Fig. H, I, J), and one-way ANOVA with post hoc Tukey test when more than two groups were compared (Fig. C, E, G, K, L, M). 


\section{Figure 2}

A
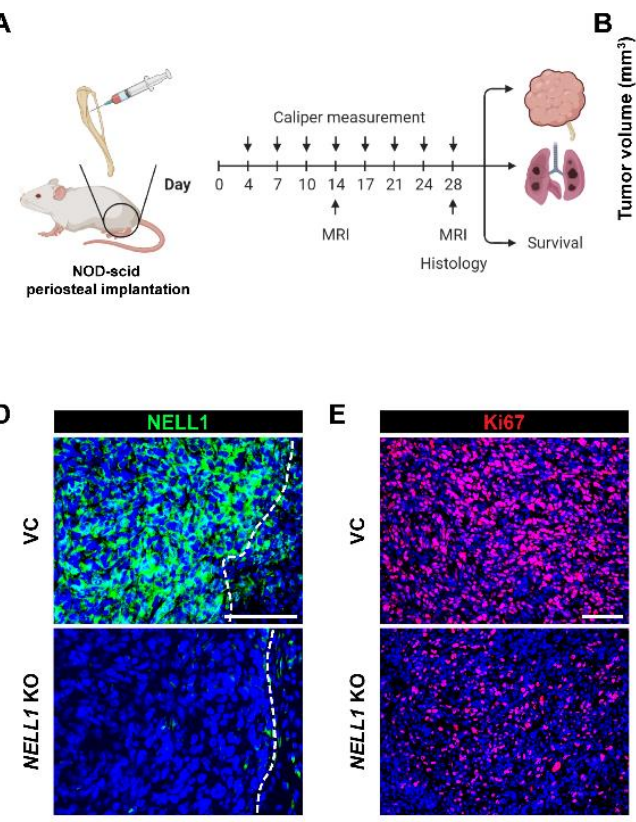

G

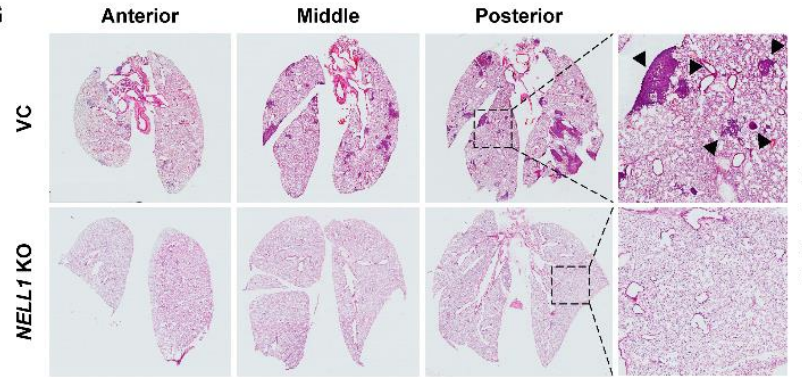

I

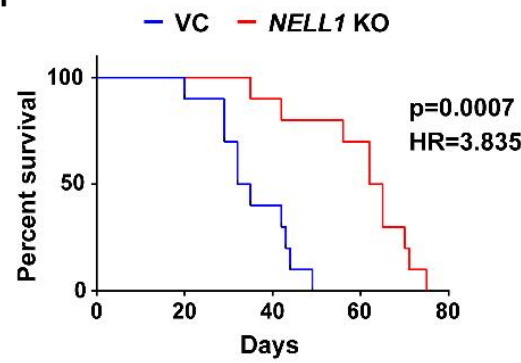

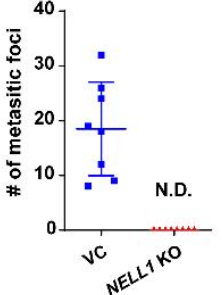

B
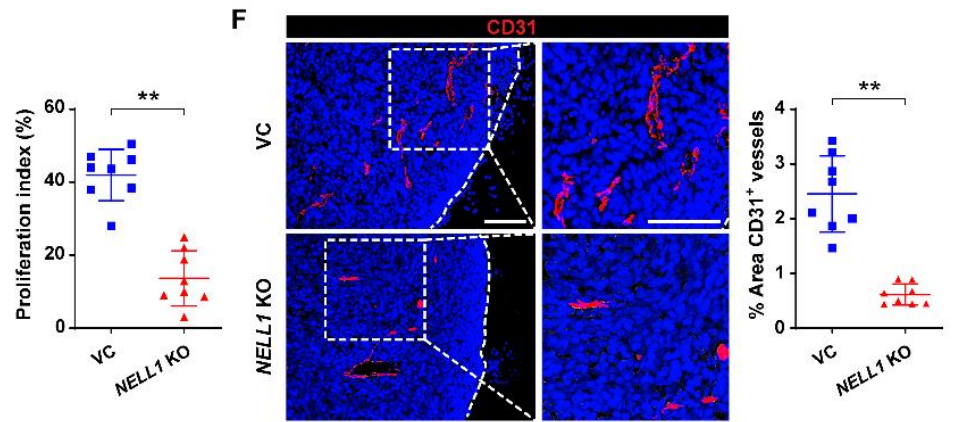

H
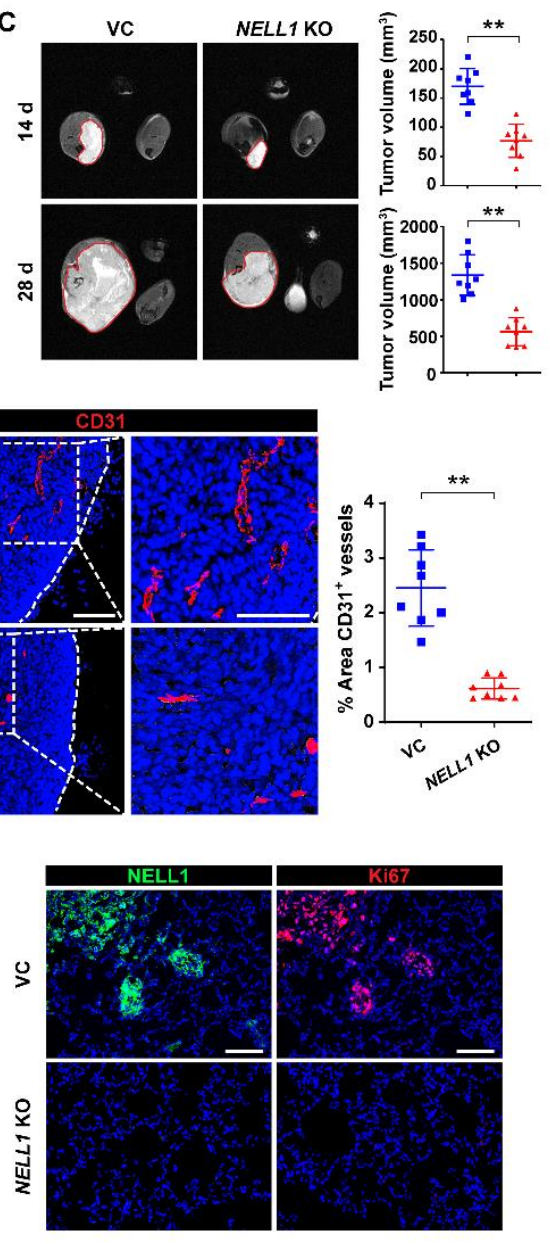

K
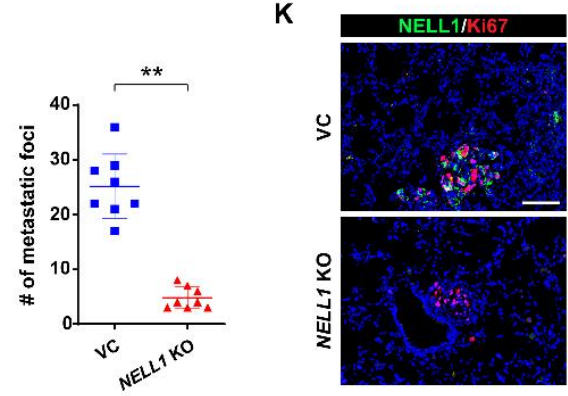


\section{Figure 2. NELL1 knockout mitigates OS disease progression in 143B xenograft model.}

Orthotopic implantation of NELL1 KO or vector control clonal 143B cells within the proximal tibia of female NOD-Scid mice ( $\mathrm{n}=8$ mice per group, $1 \times 10^{6}$ per implant). Biological replicate shown in Supplementary Fig. S4. (A) Schematic diagram of study design. (B) Tumor volume, calculated by caliper measurements twice weekly until $28 \mathrm{~d}$ post-injection (above) and gross pathology of all tumors (below). (C) Representative MRI imaging at 14 and $28 \mathrm{~d}$ post-injection (left) and tumor volume (right). (D) Confirmation of NELL1 KO in xenograft tumors by immunostaining. Dashed line indicates edge of tumor. (E) Ki67 immunostaining (left) and quantification (right). (F) CD31 immunostaining (left) and quantification (right). Dashed line indicates edge of tumor. (G) Cross-sections of pulmonary fields (left) and quantification of metastatic foci (right). (H) Representative NELL1 and Ki67 immunostaining in lung metastatic foci. (I) Overall survival, evaluated using Kaplan-Meier curves $\left(\mathrm{n}=10\right.$ mice per group, $1 \times 10^{6}$ per implant). (J) NELL1 gene deletion mitigates OS lung metastasis after systemic injection. Tail vein injection of NELL1 KO or vector control 143B cells in female NOD scid mice, followed by analysis after $28 \mathrm{~d}\left(1.5 \times 10^{6}\right.$ cells / mouse, $\mathrm{n}=8$ mice per group $)$. Cross-sections of pulmonary fields (left) and quantification of metastatic foci (right). (K) Representative NELL1 and Ki67 immunostaining in lung metastatic foci. Scale bar: $100 \mu \mathrm{m}$. Individual dots in scatterplots represent values from single animal measurements, while mean and one SD are indicated by crosshairs and whiskers. ${ }^{*} P<0.05 ; * * P<0.01$. ND: Not detected. A two-tailed student's $t$ test was used for all comparisons. Survival was assessed using Kaplan-Meier curves and log-rank analysis (Fig. I). 
bioRxiv preprint doi: https://doi.org/10.1101/2022.01.21.477245; this version posted January 23, 2022. The copyright holder for this preprint (which was not certified by peer review) is the author/funder. All rights reserved. No reuse allowed without permission.

\section{Figure 3}

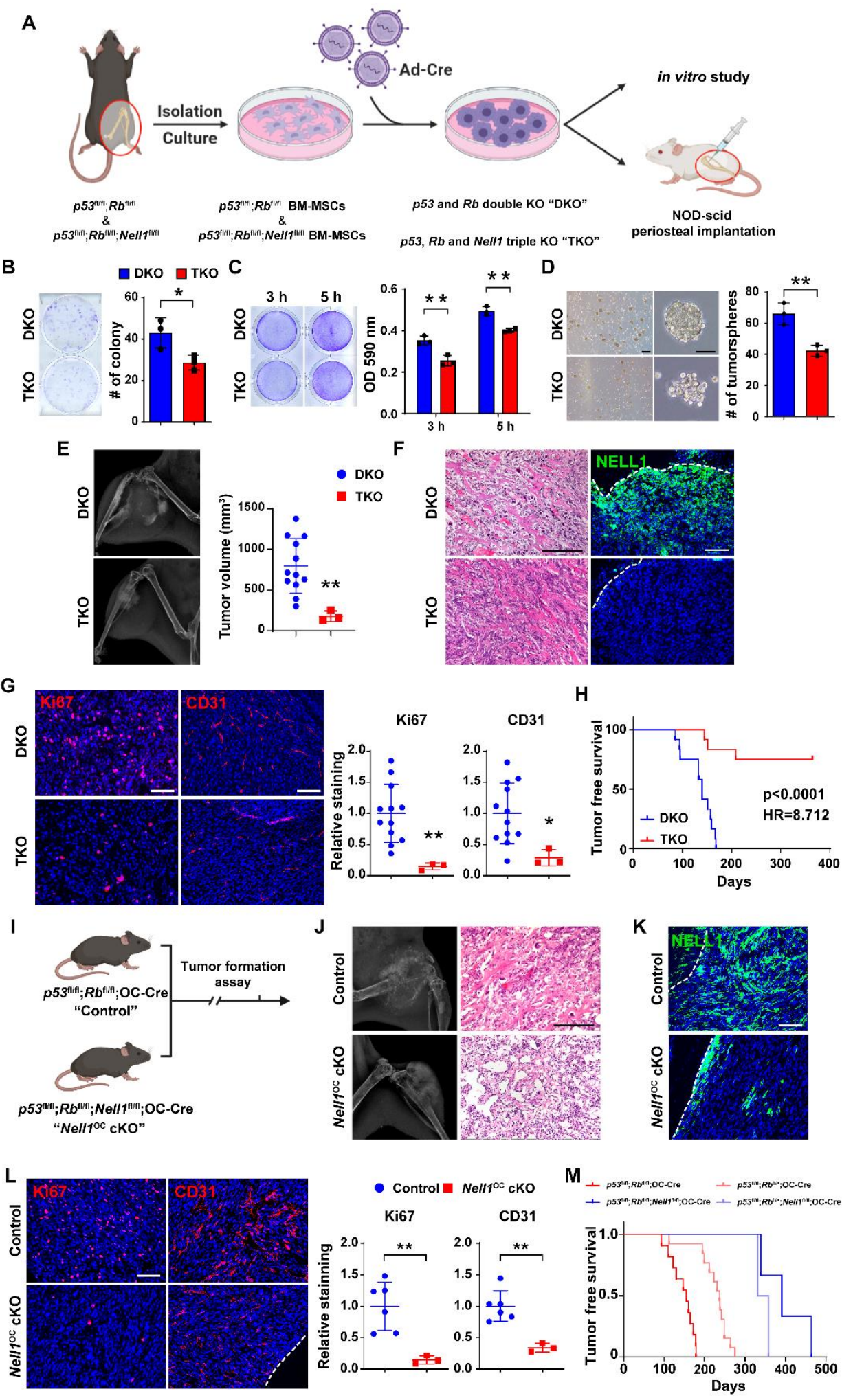


Figure 3. Nell1 gene deletion slows osteosarcomagenesis in mouse lines. (A) Schematic diagram of study design. (B-D) Effects of Adeno-Cre treatment in $p 53^{\mathrm{fl} / \mathrm{fl}} ; R b^{\mathrm{fl} / \mathrm{fl}}(\mathrm{DKO})$ or $p 53^{\mathrm{fl} / f l} ; R b^{\mathrm{fl} / / \mathrm{fl}} ; N e l l 1^{\mathrm{fl} / \mathrm{fl}}(\mathrm{TKO})$ mouse bone marrow mesenchymal stromal cells. (B) Colonyforming unit (CFU) assay, assessed by crystal violet staining (left) and quantification (right) at 10 d. (C) Attachment assay assessed by crystal violet staining (left) and quantification (right), at 3 and 5 h. (D) Tumorsphere formation assay images (left) and quantification (right) at 5 d. (E) Osteosarcomagenesis visualized by X-ray of representative tumors (left) and tumor volume calculated by caliper measurements (right). (F) Representative histologic appearance by routine H\&E staining and NELL1 immunostaining among DKO and TKO tumor tissue. (G) Representative Ki67 and CD31 immunostaining (left) and quantification (right) among DKO and TKO tumor tissues. (H) Tumor-free survival among DKO and TKO implanted mice, evaluated using Kaplan-Meier curves ( $\mathrm{n}=12$ mice per group, $1 \times 10^{6}$ per implant). (I-M) Effects of Nell1 gene deletion in spontaneous osteosarcomagenesis. (I) Schematic diagram of spontaneous osteosarcomagenesis among control $\left(p 53^{\mathrm{fl} / \mathrm{fl}} ; R b^{\mathrm{fl} / \mathrm{fl} l} ; \mathrm{OC}-\mathrm{Cre}\right)$ and $N e l l 1^{\mathrm{OC}} \mathrm{cKO}$ animals $\left(p 53^{\mathrm{fl} / / \mathrm{fl}} ; R b^{\mathrm{fl} / \mathrm{fl} l} ; N e l l 1^{\mathrm{fl} / \mathrm{fl}} ; \mathrm{OC}-\mathrm{Cre}\right) .(\mathbf{J})$ Representative X-ray images (left) and histologic appearance by routine H\&E staining (right). (K) Representative NELL1 immunostaining among control and Nell1 ${ }^{\mathrm{OC}}$ cKO tumor tissue. (L) Representative Ki67 and CD31 immunostaining (left) and quantification (right) among control and $\mathrm{Nell1}^{\mathrm{OC}} \mathrm{cKO}$ tumors. (M) Tumor-free survival, evaluated using Kaplan-Meier curves. Scale bars: $100 \mu \mathrm{m}$. For (Fig. B-D), data shown as mean \pm 1 SD with dots representing individual measurement, performed in triplicate experimental replicates. For (Fig. E, G, L), dots in scatterplots represent values from individual animal measurements, while mean and one SD are indicated by crosshairs and whiskers. $* P<0.05$; 
bioRxiv preprint doi: https://doi.org/10.1101/2022.01.21.477245; this version posted January 23, 2022. The copyright holder for this preprint (which was not certified by peer review) is the author/funder. All rights reserved. No reuse allowed without permission.

** $P<0.01$. A two-tailed student's $t$ test was used for all comparisons. For (Fig. H, M), survival was assessed using Kaplan-Meier curves and log-rank analysis. 


\section{Figure 4}

A

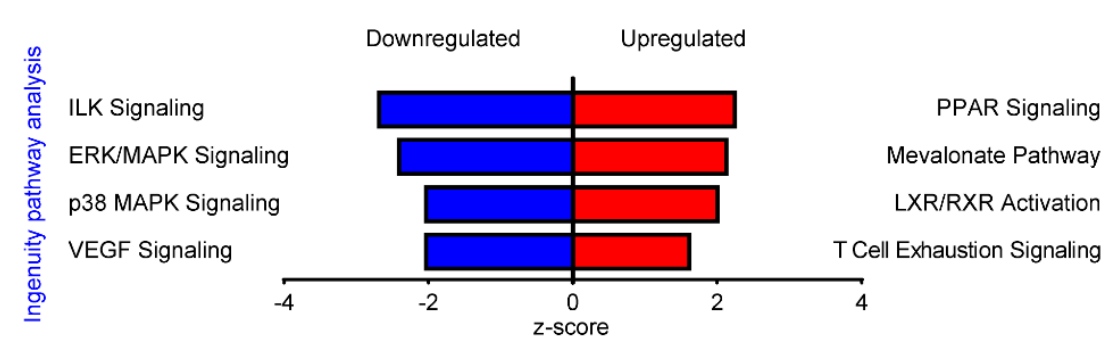

B

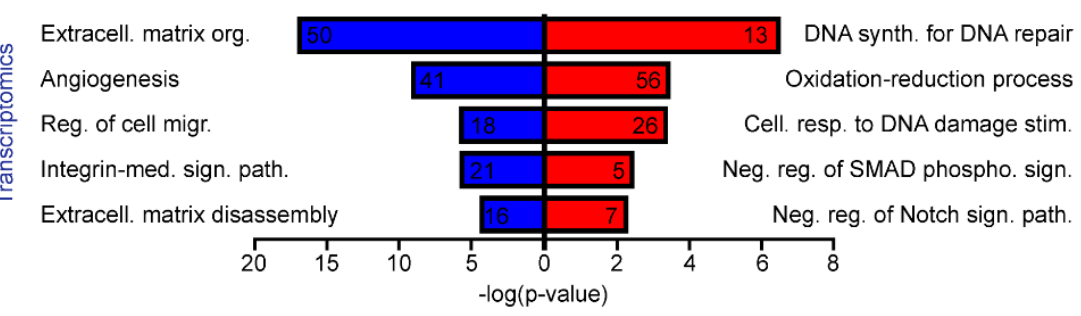

G

Pos. reg. of cell prolif.

\section{3) Multicell. organism growth}

Pos. reg. of cell migration

Pos. reg. of Notch sign. path.

Substrate adh.-depend. cell spreading

Cell. resp. to hypoxia

Glucose homeostasis

Replicative senescence Pos. reg. of cell cycle arrest
C

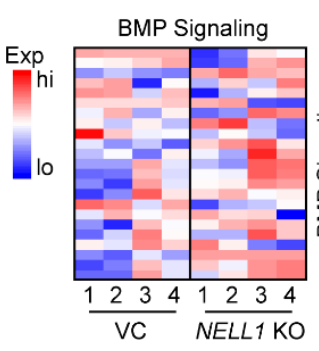

E

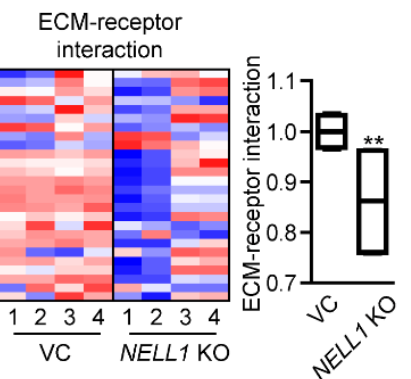

H
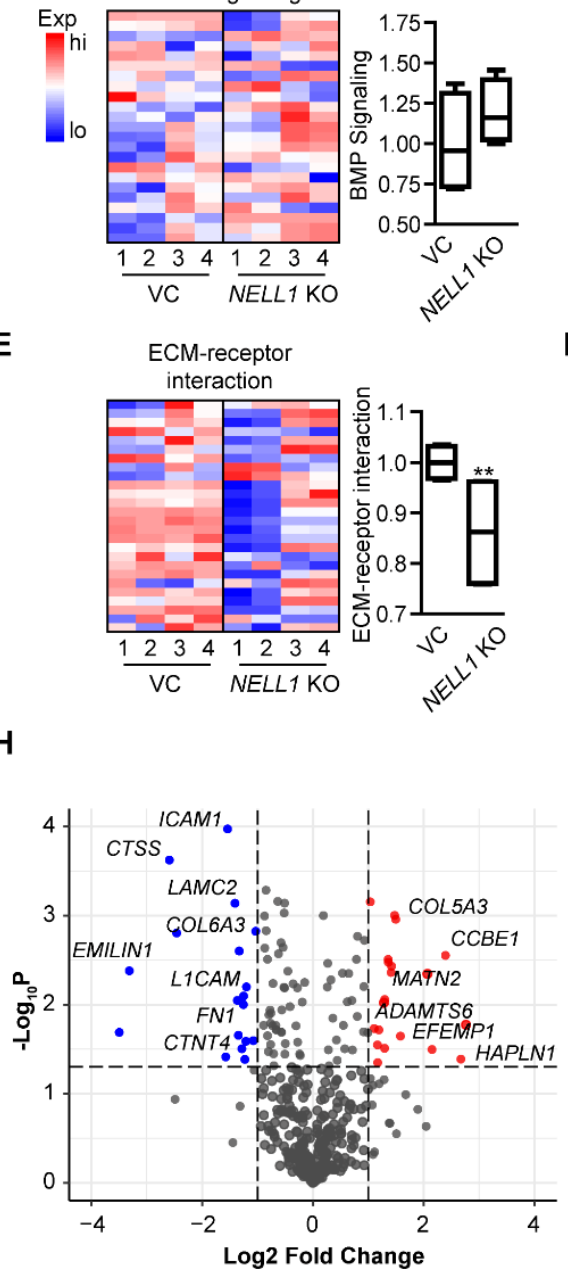

D

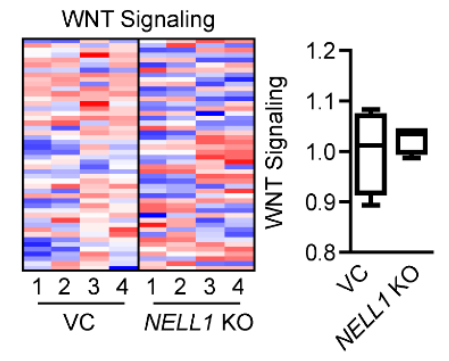

FAK Signaling
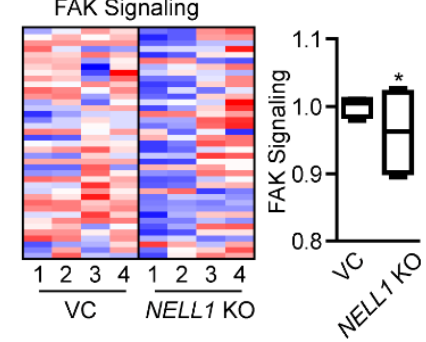

- vc

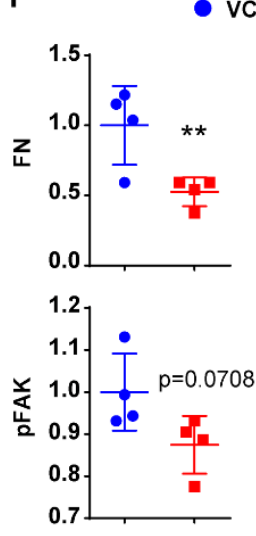

- NELL1 KO

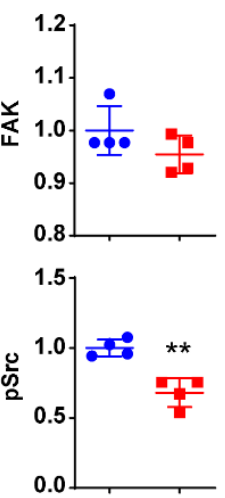

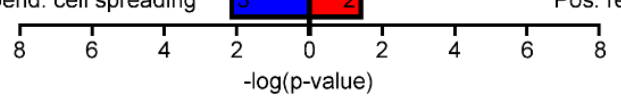

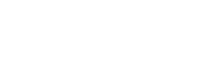


Figure 4. Bulk RNA sequencing and Reverse Phase Protein Arrays (RPPA) among NELL1

KO 143B sarcoma cells. (A) Ingenuity Pathway Analysis (IPA) analysis of downregulated pathways (Z-score < 0; blue color) or upregulated pathways (Z-score $>0$; red color) among NELL1 KO cells in comparison to vector control (VC). (B) Gene Ontology (GO) enrichment analysis identified representative pathways that were downregulated (blue color) or upregulated (red color) among NELL1 KO cells. (C-F) Heat map demonstrating expression levels of genes involved in NELL1 downstream signaling and corresponding module score among NELL1 KO as compared to VC cells, including (C) BMP signaling, (D) Wnt signaling, (E) ECM-receptor interaction, and (F) FAK signaling. (G) GO enrichment analysis identified representative pathways that were downregulated (blue color) or upregulated (red color) among NELL1 KO cells as derived from RPPA. (H) Volcano plot demonstrating transcripts of ECM components that were downregulated (blue color) or upregulated (red color) in NELL1 KO compared with VC genes derived from transcriptomics. (I) Protein expression of FAK signaling components derived from RPPA among NELL1 KO cells. $\mathrm{n}=4$ biological replicates of VC and NELL1 KO cells. Dots in scatterplots represent values from individual measurement, while mean and one SD are indicated by crosshairs and whiskers. $* P<0.05 ; * * P<0.01$. A two-tailed student's $t$ test was used for all comparisons. 
Figure 5

Xenograft Tumor

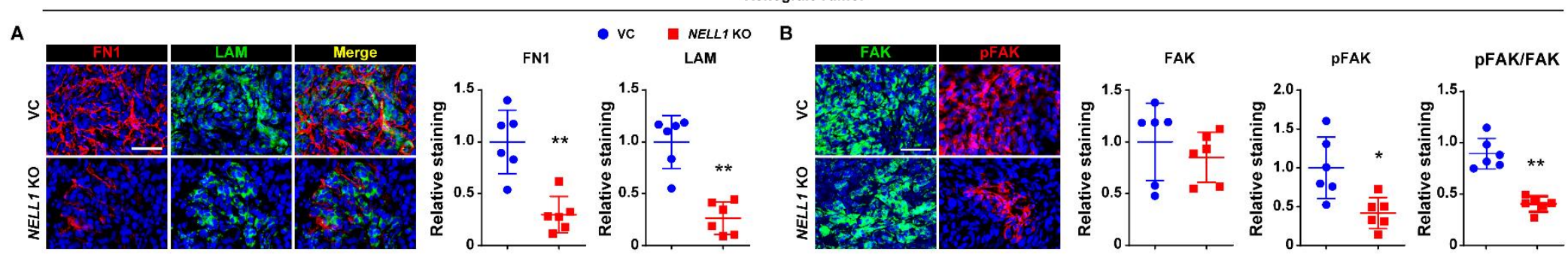

Spontaneous Tumor
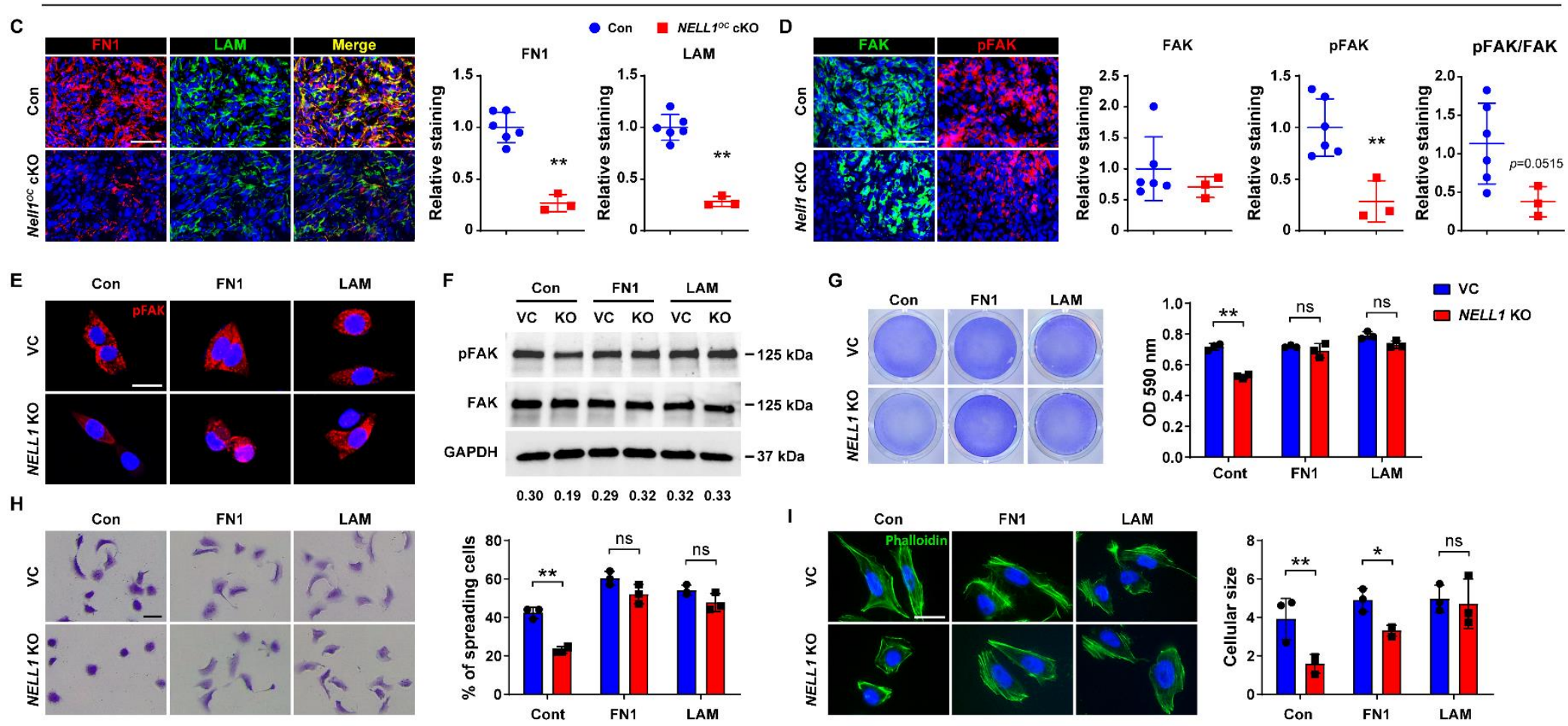


\section{Figure 5. Sarcoma-associated ECM proteins positively regulate FAK signaling and} adhesive features in NELL1 KO sarcoma cells. (A, B) Immunohistochemical analysis of 143B OS cell implants among VC and NELL1 KO tumor tissue, $28 \mathrm{~d}$ post-implantation. (A) Representative Fibronectin (FN1) and laminin (LAM) immunostaining (left) and quantification (right). (B) Representative FAK and pFAK immunostaining (left) and quantification (right). (C, D) Immunohistochemical analysis of mouse spontaneous OS tumor tissues from control $\left(p 53^{\mathrm{fl} / \mathrm{fl}} ; R b^{\mathrm{fl} / / \mathrm{fl}} ; \mathrm{OC}-\mathrm{Cre}\right)$ or $N e l l 1^{\mathrm{OC}} \mathrm{cKO}\left(p 53^{\mathrm{fl} / \mathrm{fl}} ; R b^{\mathrm{fl} / \mathrm{fl}} ; N e l l 1^{\mathrm{fl} / \mathrm{fl}} ; \mathrm{OC}-\mathrm{Cre}\right)$ animals. (C) Representative FN1 and LAM immunostaining (left) and quantification (right). (D) Representative FAK and pFAK immunostaining (left) and quantification (right) among control and Nell1 $^{\mathrm{OC}} \mathrm{cKO}$ tumors. (E-I) Effects of sarcoma ECM components fibronectin (FN1) or laminin (LAM) on 143B OS cells with or without NELL1 KO. Comparisons made to vector control (VC) treated cells. Pre-coated wells include FN1 (10 $\mu \mathrm{g})$ and LAM (10 $\mu \mathrm{g})$. (E) Representative pFAK immunostaining at $3 \mathrm{~h}$ post-seeding. (F) Western blot of pFAK and FAK at $5 \mathrm{~h}$ postseeding. Ratio of pFAK/FAK listed below. (G) Attachment assay assessed by crystal violet staining (left) and quantification (right) at $5 \mathrm{~h}$ post-seeding. (H) Cell spreading assay assessed by crystal violet staining (left) and quantification (right) at $3 \mathrm{~h}$. (I) Representative phalloidin staining (left) and quantification (right) at $3 \mathrm{~h}$. Scale bar: $50 \mu \mathrm{m}(\mathbf{A}-\mathbf{D})$, and $20 \mu \mathrm{m}(\mathbf{E}, \mathbf{H}, \mathbf{I})$. In (A-D), dots in scatterplots represent values from individual animal measurements, while mean and one SD are indicated by crosshairs and whiskers. In (E-G), data shown as mean $\pm 1 \mathrm{SD}$, with dots representing individual wells, performed in triplicate experimental replicates. $* P<0.05$; $* * P<0.01$. ns: non-significant. A two-tailed student's $t$ test was used for all comparisons. 


\section{Figure 6}

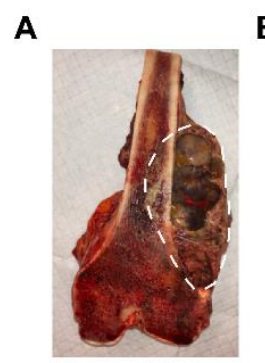

\section{B 4)} AB

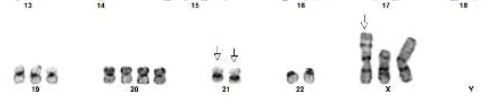
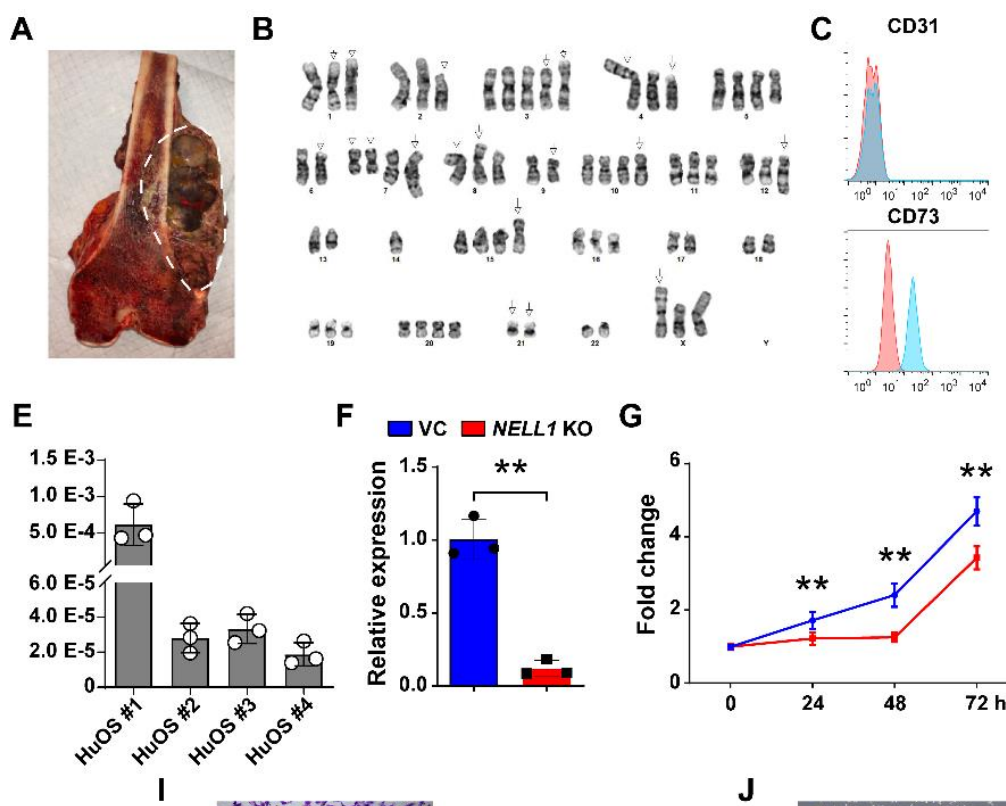

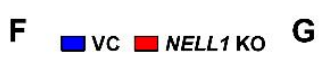

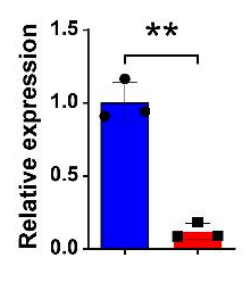

\section{G}
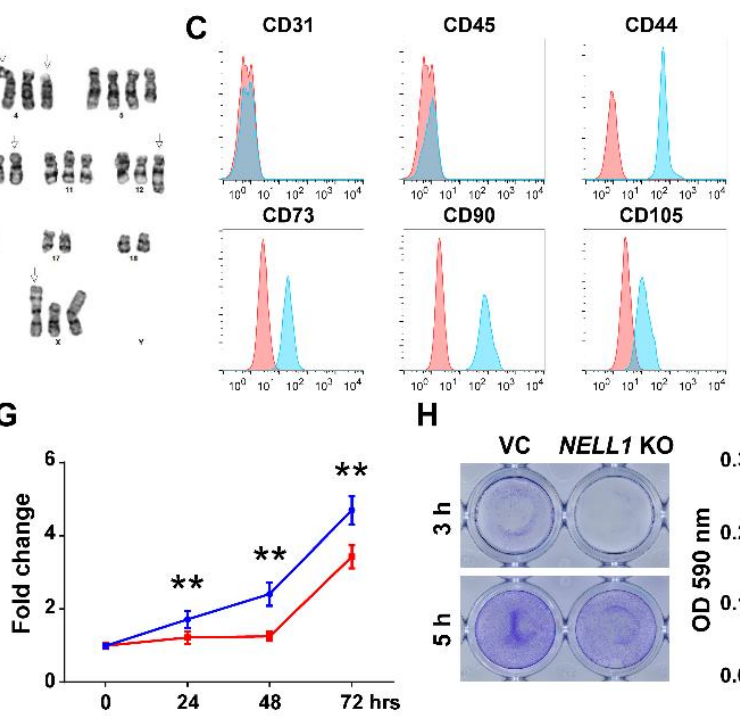

D
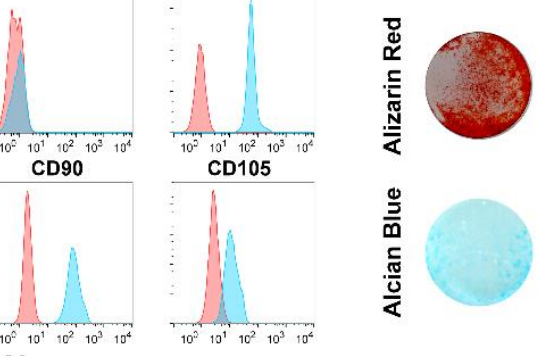

H
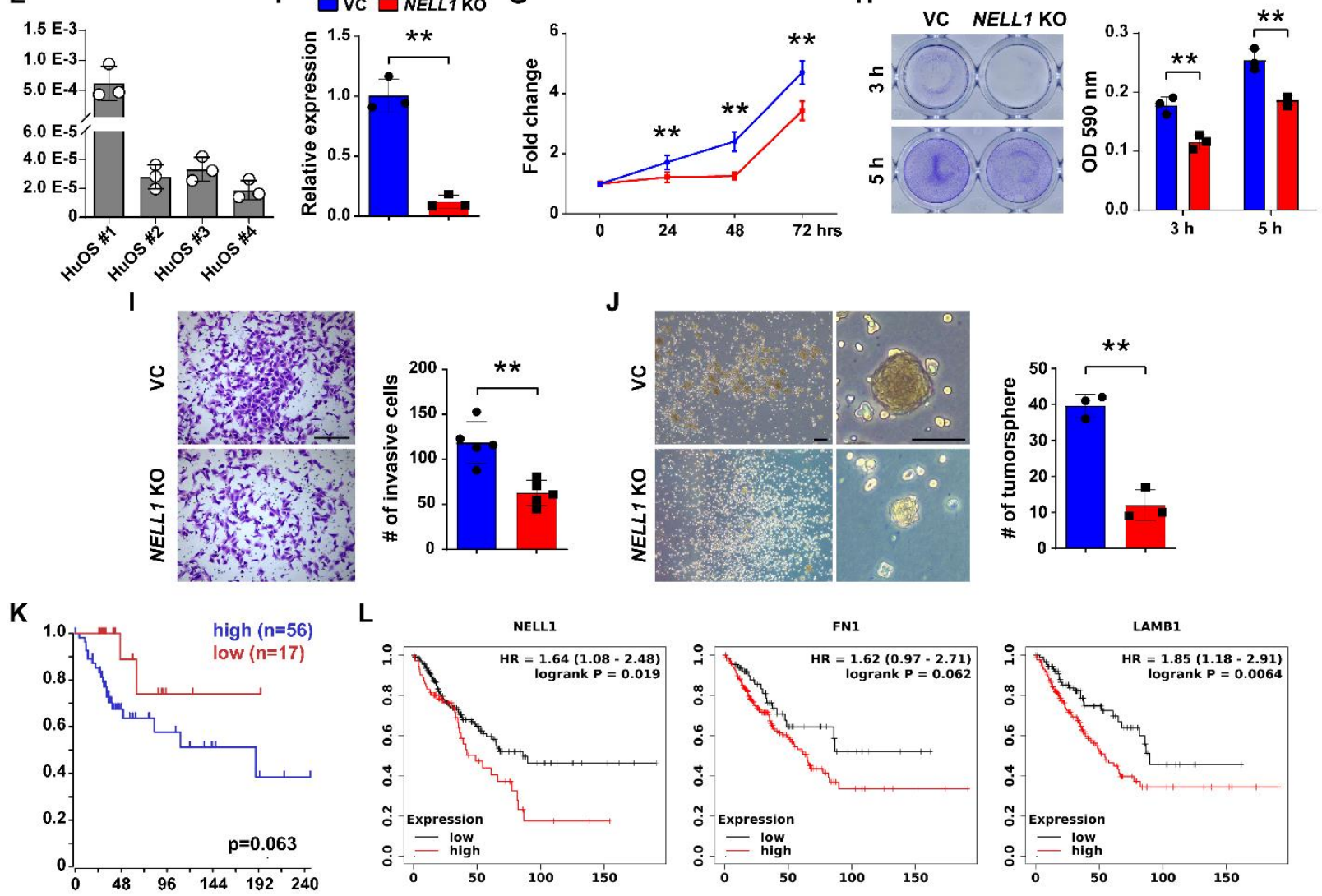

M
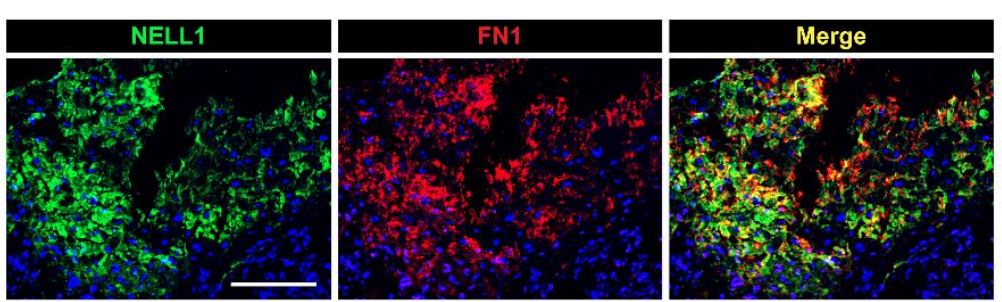

N

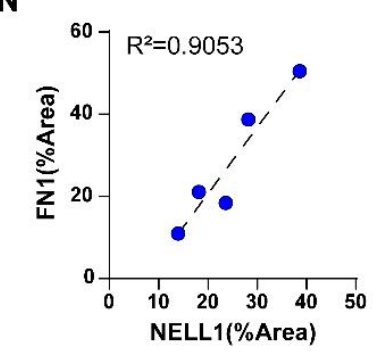




\section{Figure 6. $N E L L 1$ regulates invasive potential in primary human OS cells and is associated} with disease progression in human patients. (A) Representative image of bisected osteosarcoma sample. White dashed lines indicate tumor. (B) Representative karyotype of primary osteosarcoma cells. (C) Representative flow cytometry analysis of patient-derived primary osteosarcoma cells. Frequency of expression is shown (blue) in relation to isotype control (red). (D) Representative Alizarin red (AR) at d 10 of osteogenic differentiation, and Alcian blue staining at d 14 of chondrogenic differentiation among human OS cells. (E) NELL1 expression in primary osteosarcoma cells by qRT-PCR. (F-J) Effects of NELL1 gene deletion in primary osteosarcoma cells. (F) Confirmation of NELL1 gene deletion efficiency by qRT-PCR. (G) MTS proliferation assay among NELL1 KO primary osteosarcoma cells at 24, 48, and $72 \mathrm{~h}$. (H) Attachment assay assessed by crystal violet staining and quantification, at 3 and $5 \mathrm{~h}$. (I) Transwell invasion assay and quantification, at $24 \mathrm{~h}$. Representative images with number of invasive cells shown. Scale bars: $500 \mu \mathrm{m}$. (J) Tumorsphere formation assay and quantification at 5 d. (K) Prognostic value of NELL1 in patients with high grade osteosarcoma. Kaplan-Meier curve generated by R2 genomics analysis and visualization platform. (L) Prognostic value of NELL1, FN1, and LAMB1 in high grade sarcoma patients. Kaplan-Meier curve generated by Kaplan-Meier (KM) plotter pan-caner RNA seq. (M) Representative NELL1 and Fibronectin immunofluorescent staining in biopsy samples of high grade conventional osteosarcoma. (N) Correlation of NELL1 and Fibronectin staining across N=5 biopsy samples of high grade conventional osteosarcoma. Scale bars: $100 \mu \mathrm{m}$. Data shown as mean $\pm 1 \mathrm{SD}$, and represent triplicate experimental replicates. ${ }^{*} P<0.05 ; * * P<0.01$. A two-tail Student's $t$ test was used for two group comparisons. 


\section{Supplementary Fig. S1}

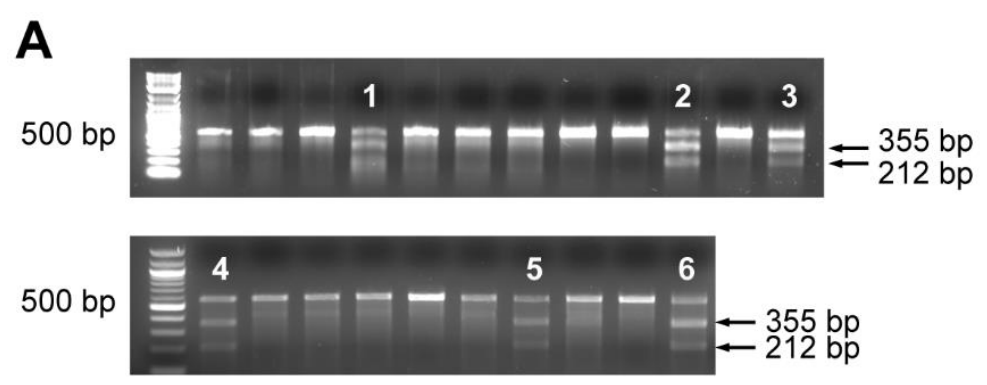

B

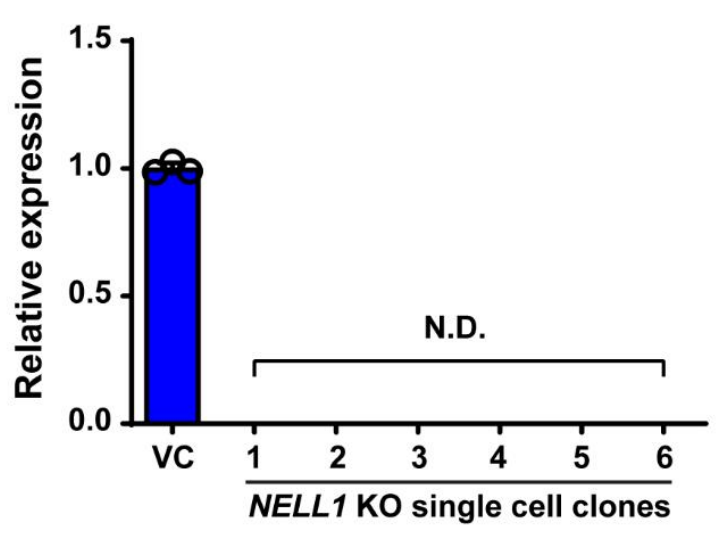

Fig. S1. Validation of CRISPR-Cas9 mediated NELL1 KO efficiency. Confirmation of NELL1 knockout (KO) in six single cell clones by (A) T7 endonuclease I assay and (B) qRTPCR. (A) The arrows indicate the cleaved PCR products corresponding to 355 and $212 \mathrm{bp}$ respectively. (B) Relative expression of NELL1 in six clones compared with vector control (VC). Data shown as mean $\pm 1 \mathrm{SD}$, with dots representing individual datapoints. All experiments performed in triplicate replicates, with results from a single replicate shown. ND: Not detected. 


\section{Supplementary Fig. S2}
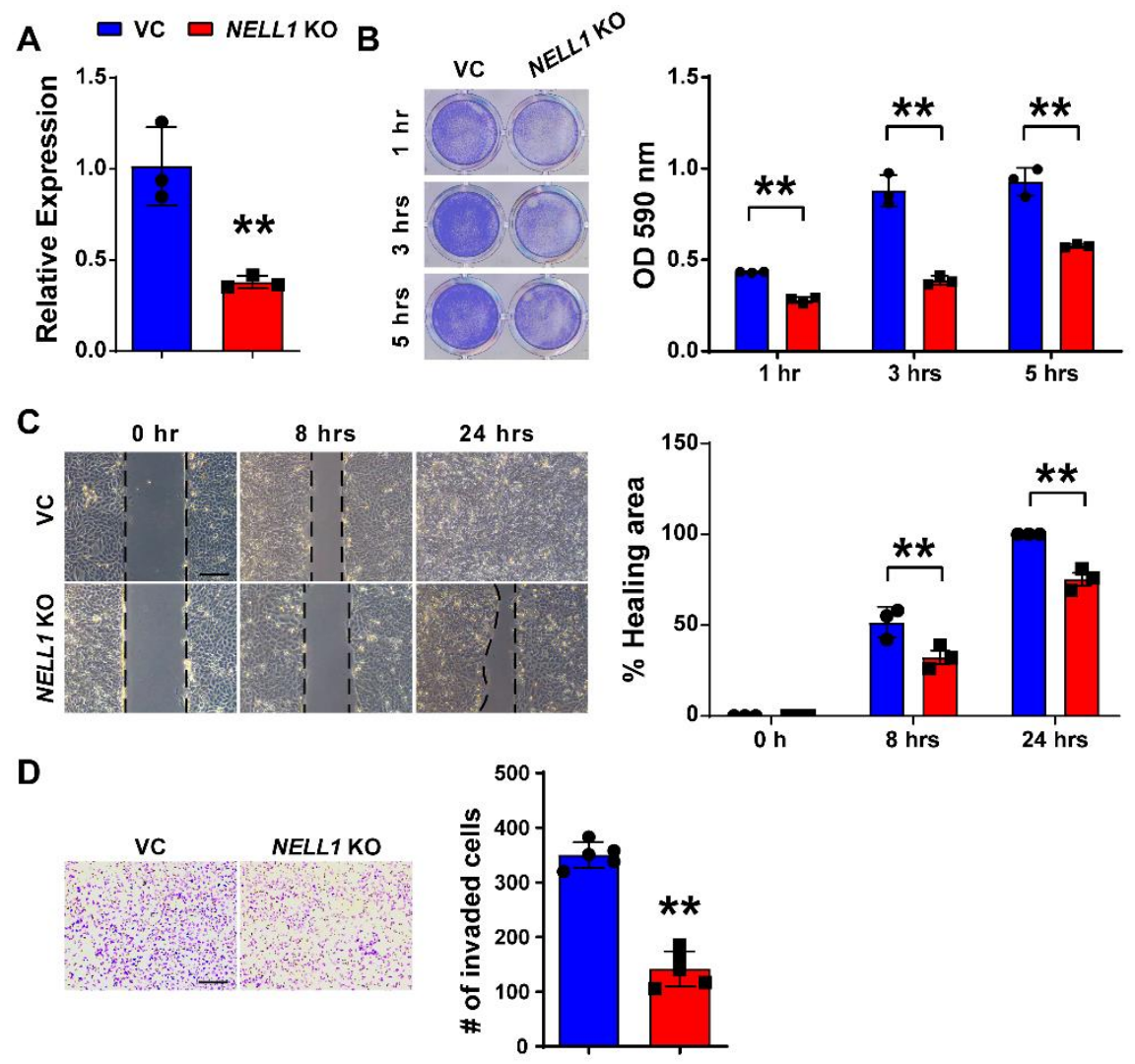

Fig. S2. CRISPR-Cas9 mediated NELL1 KO in polyclonal 143B cells. (A) Confirmation of NELL1 gene deletion efficiency by qRT-PCR, in comparison to VC. (B-D) Effects of CRISPRmediated NELL1 gene deletion in polyclonal 143B OS cells. (B) Attachment assay as assessed by crystal violet staining (left) and quantification (right) with or without NELL1 KO (1-5 h). (C) Scratch wound healing assay with or without NELL1 KO. Representative images (left) with percentage wound healing (right) (8 and 24 h). (D) Transwell invasion assay with or without NELL1 KO (24 h). Representative images (left) with number of invaded cells (right). Data shown as mean $\pm 1 \mathrm{SD}$, with dots representing individual datapoints. All experiments performed in triplicate replicates, with results from a single replicate shown. $* * P<0.01$. Scale bars: $500 \mu \mathrm{m}$. A two-tail Student's $t$ test was used for two group comparisons. 


\section{Supplementary Fig. S3}
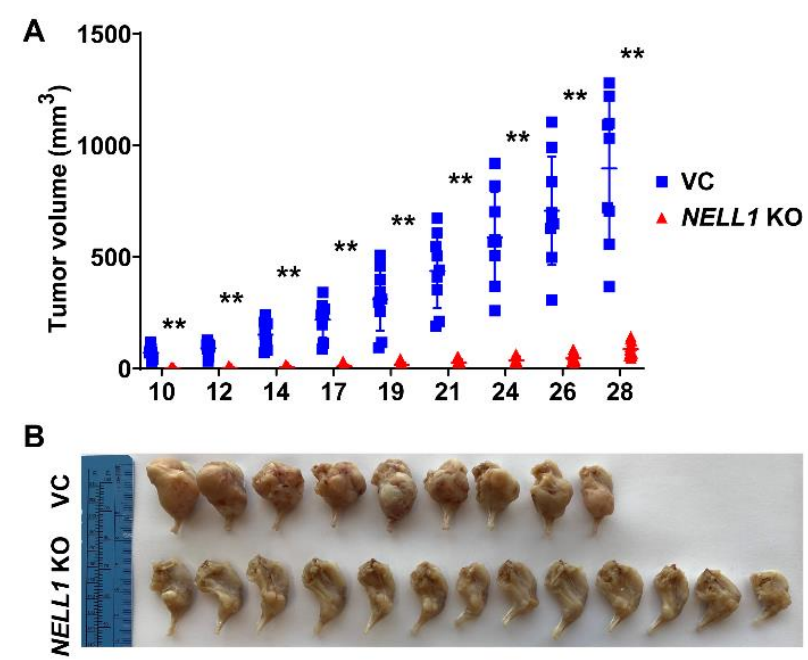

C

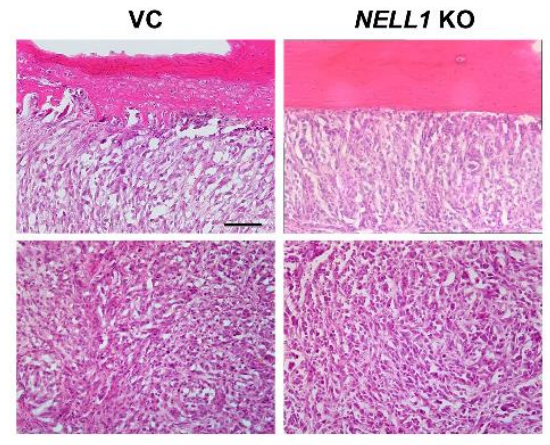

Fig. S3. NELL1 gene deletion mitigates OS disease progression. Biologic replicate of data shown in Fig. 3B. Orthotopic implantation of NELL1 KO or vector control (VC) 143B cells within the proximal tibial metaphysis in NOD-Scid mice ( $\mathrm{n}=9$ VC implants and $\mathrm{n}=13$ NELL1 KO implants, $1 \times 10^{6}$ cells per implant). (A) Tumor volume, calculated by caliper measurements until 28 d post-injection. (B) Gross pathology of all tumors. (C) Representative histologic appearance by routine $\mathrm{H} \& \mathrm{E}$ staining, adjacent to the tibial cortex (above) and a representative central area of tumor (below). Scale bars: $200 \mu \mathrm{m}$. Dots in scatterplots represent values from individual implants, while mean and one SD are indicated by crosshairs and whiskers. $* * P<0.01$. A two-tailed student's t test was used for all comparisons. 


\section{Supplementary Fig. S4}

A

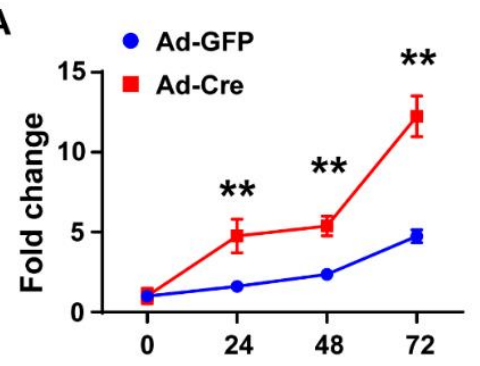

C

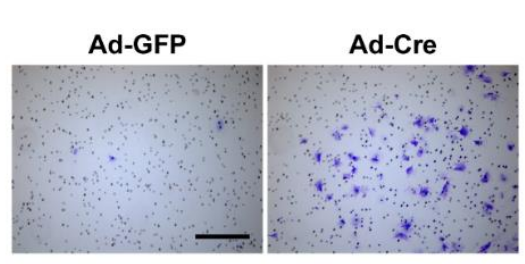

D

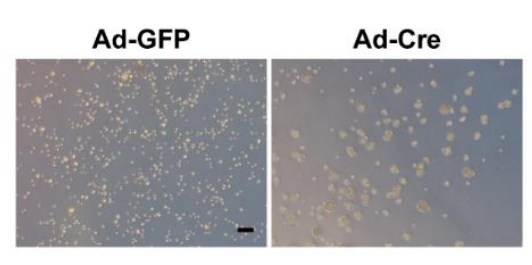

B
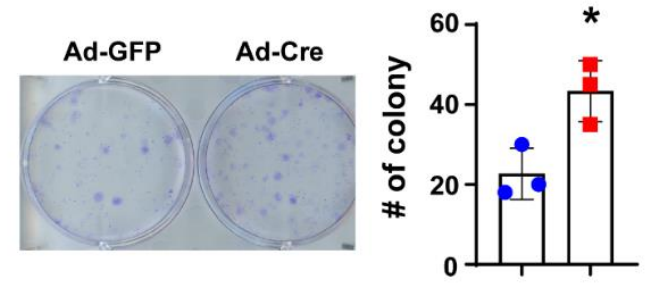
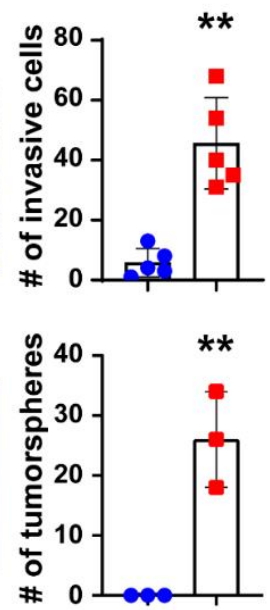

Fig. S4. Cellular behavior after adenovirus-mediated p53/Rb gene deletion in mouse

BMSCs. BMSCs were isolated from $p 53^{\mathrm{fl} / f 1} ; R b^{\mathrm{fl} / \mathrm{fl}}$ mice and transfected with either Ad-GFP or Ad-Cre (200 MOI). (A) MTS proliferation assay at up to 72 h. (B) Colony-forming unit (CFU) assay assessed by crystal violet staining (left) and quantification (right) at $10 \mathrm{~d}$. (C) Invasion assessed by transwell assay, crystal violet staining (left) and quantification (right) at $24 \mathrm{~h}$. (D) Tumorsphere formation assay (left) and quantification (right) at $5 \mathrm{~d}$. Scale bars: $100 \mu \mathrm{m}$. Data shown as mean $\pm 1 \mathrm{SD}$, and represent triplicate experimental replicates. Dots in scatterplots represent values from individual wells. $* P<0.05$; $* * P<0.01$. A two-tailed student's t test was used for all comparisons. 


\section{Supplementary Fig. S5}

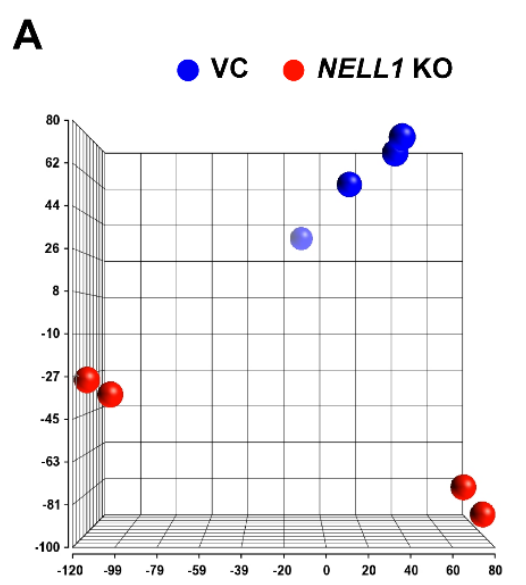

C

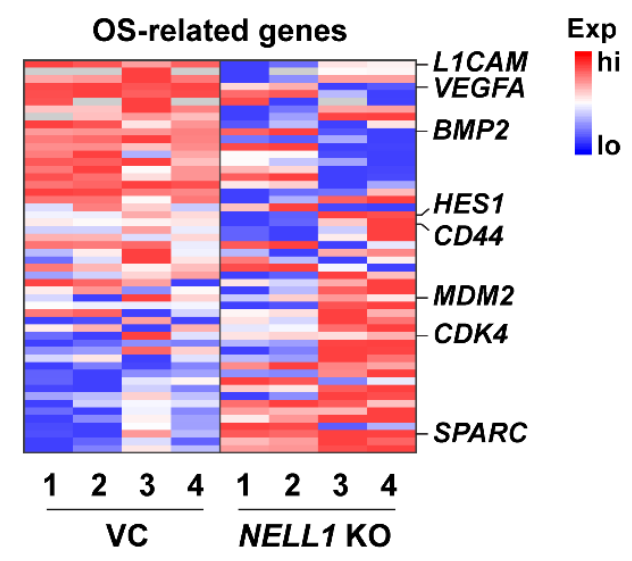

B

Exp

hi

lo

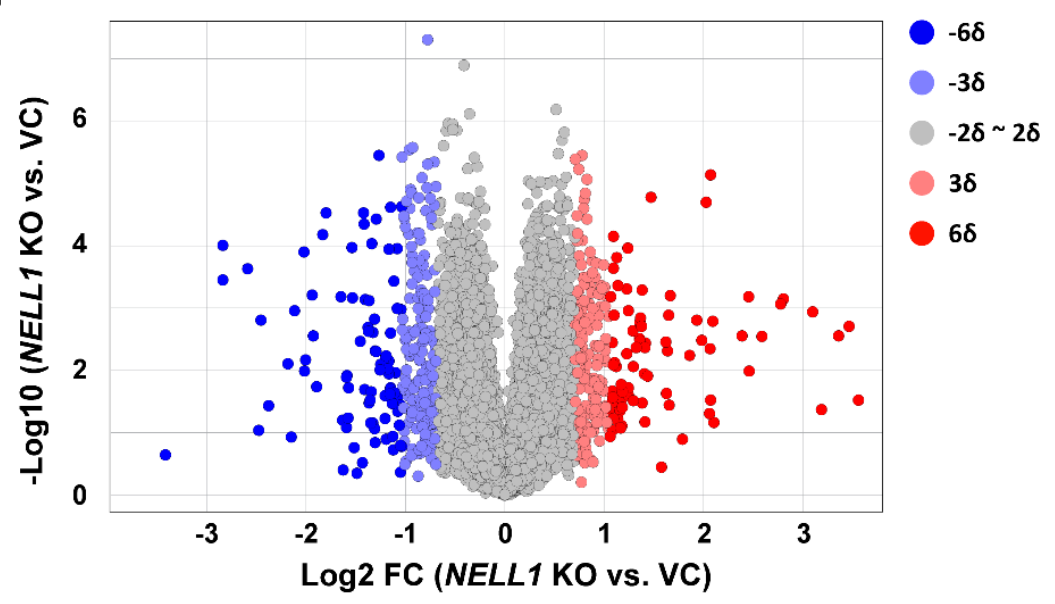

Fig. S5. Additional transcriptomic analysis of clonal 143B cells with or without $N E L L 1$

gene deletion. (A) Principal component analysis among VC and NELL1 KO osteosarcoma cells. (B) Volcano plot of 54,174 protein coding genes expressed among VC and NELL1 KO 143B cells. Red dots indicate $>2$ SD increase among NELL1 KO cells. Blue dots indicate $>2$ SD decrease among NELL1 KO cells. (C) Heat map indicating OS-related gene expression among VC and NELL1 KO osteosarcoma cells, with some representative genes listed. See

Supplementary Table S8 for a detailed gene list. $\mathrm{n}=4$ biological replicates of VC and NELL1 KO 143B OS cells. 


\section{Supplementary Fig. S6}

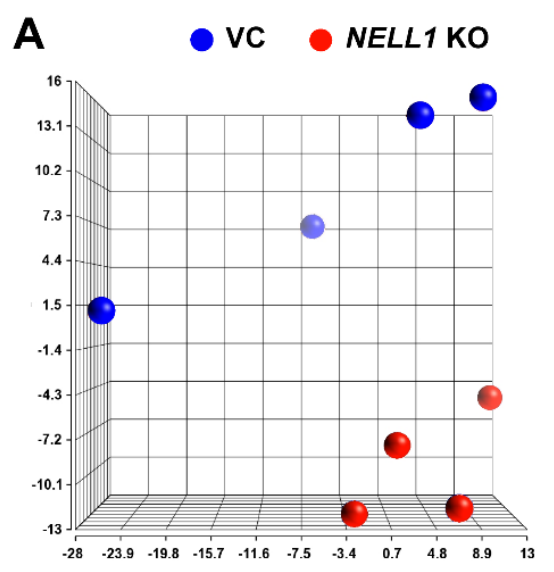

C

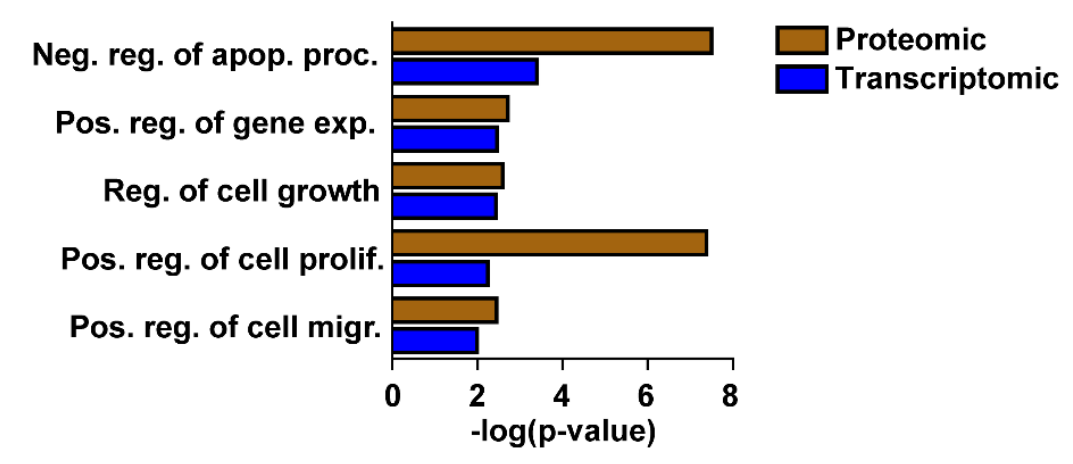

B

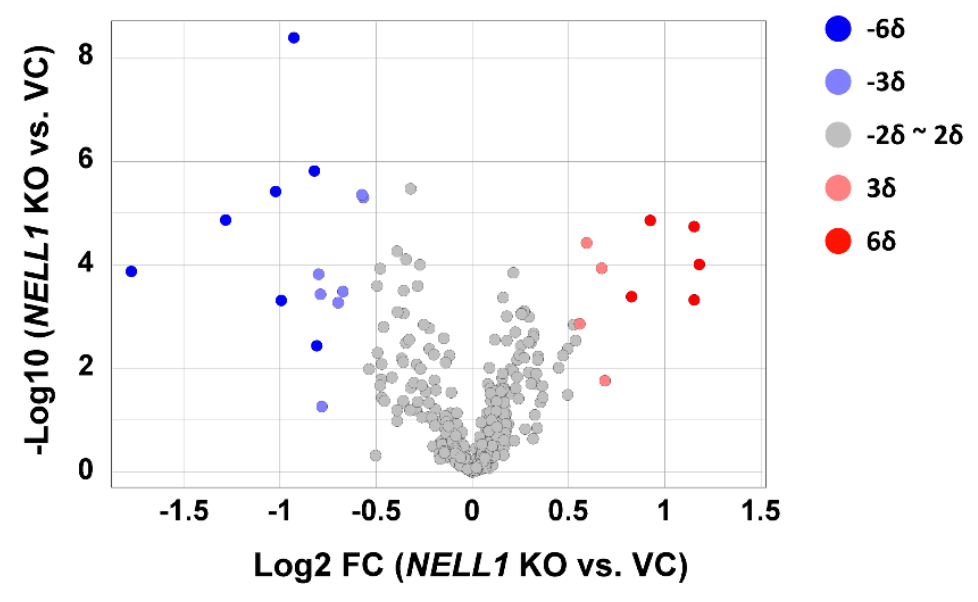

Fig. S6. Additional proteomic analysis of clonal 143B cells with or without NELL1 gene

deletion. (A) Principal component analysis among VC and NELL1 KO cells. (B) Volcano plot of 453 proteins expressed among $\mathrm{VC}$ and NELL1 KO cells. Red dots indicate $>2$ SD increase among NELL1 KO cells. Blue dots indicate >2SD decrease among NELL1 KO cells. (C) Shared GO terms enriched in both transcriptomic and proteomic analysis in NELL1 KO cells. $\mathrm{n}=4$ biological replicates of VC and NELL1 KO cells. 


\section{Supplementary Fig. S7}
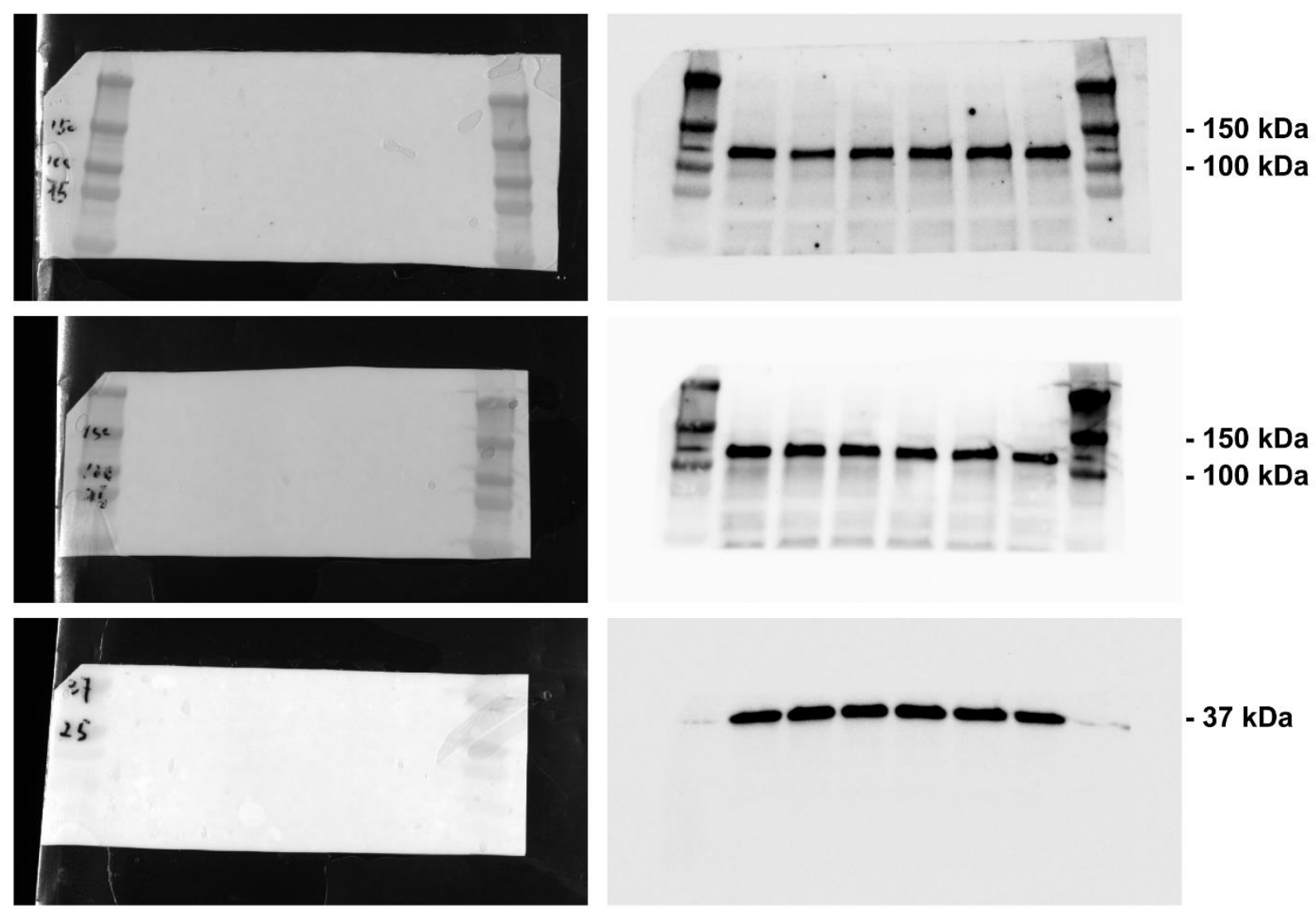

- 37 kDa

Fig. S7. Full-size blots of Figure 5I. 


\section{Supplementary Fig. S8}
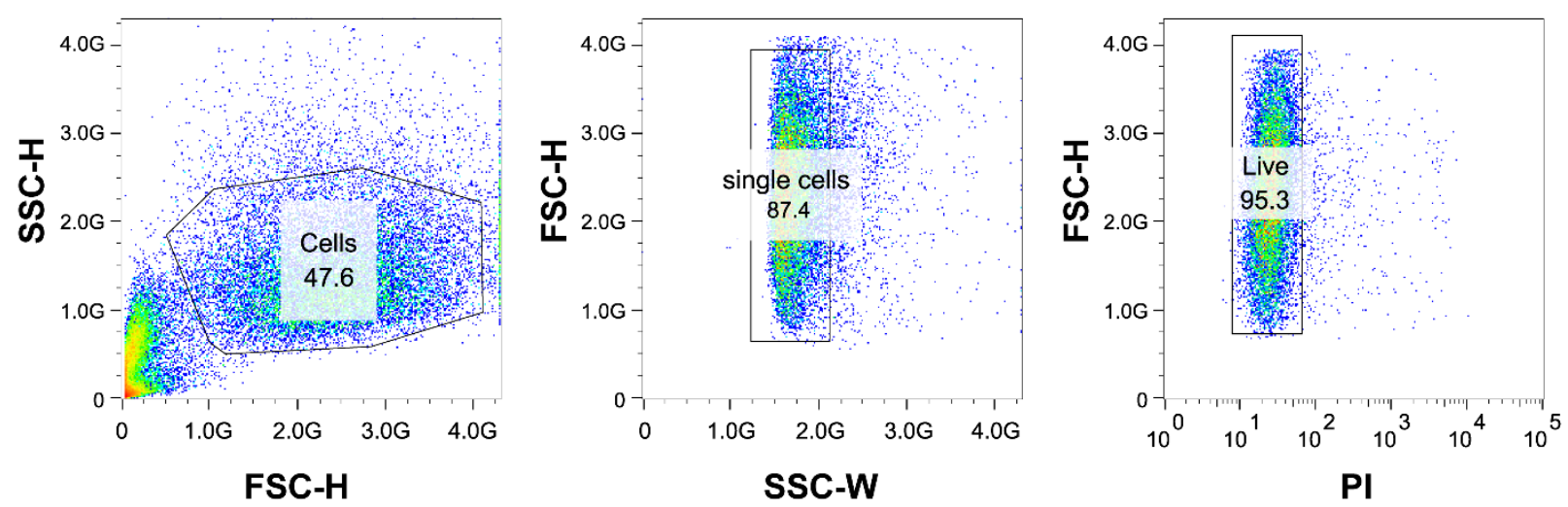

Fig. S8. Representative flow cytometry of primary OS cells used in Figure 6C. 
Supplementary Table S1. Tumor penetrance for mouse cell implantation model.

\begin{tabular}{ccccc}
\hline Cell treatment & $\begin{array}{c}\text { Total } \\
\text { animals } \\
(\mathrm{N})\end{array}$ & $\begin{array}{c}\text { Animals with } \\
\text { tumors (N) }\end{array}$ & Penetrance & $\begin{array}{c}\text { Mean latency in days } \pm \\
\text { 1 SD (range) }\end{array}$ \\
\hline $\begin{array}{c}p 53^{\mathrm{fl} / \mathrm{fl} l} ; R b^{\mathrm{fl} / \mathrm{fl}} ; \mathrm{Cre}^{+} \\
(\mathrm{DKO}) \text { mouse BMSC }\end{array}$ & 12 & 12 & $100 \%$ & $135.2 \pm 29(85-168)$ \\
$\begin{array}{c}p 53^{\mathrm{fl} / \mathrm{fl}} ; R b^{\mathrm{fl} / \mathrm{fl}} ; N e l l 1^{\mathrm{fl} / \mathrm{fl} ;} \\
\mathrm{Cre}^{+}(\mathrm{TKO}) \text { mouse } \\
\text { BMSC }\end{array}$ & 12 & 3 & $25 \%$ & $168.0 \pm 34.8(145-208)$ \\
\hline
\end{tabular}


Supplementary Table S2. Summary of tumor formation within spontaneous OS mouse model with or without Nell1 gene deletion.

\begin{tabular}{|c|c|c|c|c|c|c|c|c|c|c|}
\hline \multicolumn{4}{|c|}{ Genotype } & \multirow{2}{*}{$\begin{array}{l}\text { Total } \\
\text { animals } \\
(\mathrm{N})\end{array}$} & \multirow{2}{*}{$\begin{array}{l}\text { Animals } \\
\text { with } \\
\text { tumors } \\
(\mathrm{N}) \\
\end{array}$} & \multicolumn{2}{|c|}{ Sex distribution } & \multirow{2}{*}{ Penetrance } & \multirow{2}{*}{$\begin{array}{c}\text { Mean latency in days } \\
\pm 1 \mathrm{SD} \\
\text { (range) }\end{array}$} & \multirow{2}{*}{$\begin{array}{c}\mathrm{p} \text {-value } \\
\text { (compared with } \\
\text { corresponding } \\
\text { NellI }^{+/+} \text {) }\end{array}$} \\
\hline $\begin{array}{l}\text { OC- } \\
\text { Cre }\end{array}$ & p53 & $R b$ & Nell1 & & & Male $(\mathrm{N})$ & $\begin{array}{c}\text { Female } \\
(\mathrm{N})\end{array}$ & & & \\
\hline+ & $\mathrm{fl} / \mathrm{fl}$ & $\mathrm{fl} / \mathrm{fl}$ & $+/+$ & 21 & 11 & 4 & 7 & $52.4 \%$ & $\begin{array}{c}146.5 \pm 28.9 \\
(93-179)\end{array}$ & \\
\hline+ & $\mathrm{fl} / \mathrm{fl}$ & $\mathrm{fl} /+$ & $+/+$ & 21 & 10 & 6 & 4 & $47.6 \%$ & $\begin{array}{c}225.3 \pm 47.1 \\
(112-275)\end{array}$ & \\
\hline+ & $\mathrm{fl} / \mathrm{fl}$ & $\mathrm{fl} / \mathrm{fl}$ & $\mathrm{fl} / \mathrm{fl}$ & 19 & 3 & 1 & 2 & $15.8 \%$ & $\begin{array}{c}398 \pm 62.8 \\
(339-464)\end{array}$ & $<0.0001$ \\
\hline+ & $\mathrm{fl} / \mathrm{fl}$ & $\mathrm{fl} /+$ & $\mathrm{fl} / \mathrm{fl}$ & 18 & 2 & 1 & 1 & $11.1 \%$ & $\begin{array}{c}344.5 \pm 19.1 \\
(331-358) \\
\end{array}$ & 0.0066 \\
\hline
\end{tabular}


Supplementary Table S3. Summary of spontaneous OS tumors location and incidence.

\begin{tabular}{ccccccc}
\hline \multicolumn{3}{c}{ Genotype } & & & \\
\cline { 1 - 1 } $\begin{array}{c}\text { OC- } \\
\text { Cre }\end{array}$ & $p 53$ & $R b$ & Nell1 & & Location & Number (Ratio) \\
\hline+ & $\mathrm{fl} / \mathrm{fl}$ & $\mathrm{fl} / \mathrm{fl}$ & $+/+$ & & Rib/vertebra & $1(9.1 \%)$ \\
& & & & & Forelimb & $3(27.3 \%)$ \\
& & & & Hindlimb & $7(63.6 \%)$ \\
\hline+ & $\mathrm{fl} / \mathrm{fl}$ & $\mathrm{fl} / \mathrm{fl}$ & $\mathrm{fl} / \mathrm{fl}$ & & Forelimb & $2(66.7 \%)$ \\
& & & & & Hindlimb & $1(33.3 \%)$ \\
\hline
\end{tabular}


Supplementary Table S4: Most downregulated pathways among NELL1 KO clonal 143B cells by Ingenuity Pathway Analysis.

\begin{tabular}{|c|c|c|}
\hline Pathway & Z score & $\begin{array}{l}-\log p- \\
\text { value } \\
\end{array}$ \\
\hline Dendritic Cell Maturation & -2.84 & 4.4 \\
\hline ILK Signaling & -2.646 & 0.955 \\
\hline ERK/MAPK Signaling & -2.646 & 0.629 \\
\hline Coronavirus Pathogenesis Pathway & -2.53 & 2.33 \\
\hline GP6 Signaling Pathway & -2.496 & 4.98 \\
\hline $\begin{array}{l}\text { Production of Nitric Oxide and Reactive Oxygen Species in } \\
\text { Macrophages }\end{array}$ & -2.449 & 0.455 \\
\hline p38 MAPK Signaling & -2.333 & 2.43 \\
\hline IL-6 Signaling & -2.333 & 2.26 \\
\hline Acute Phase Response Signaling & -2.333 & 2.15 \\
\hline$N F-\kappa B$ Signaling & -2.333 & 1.4 \\
\hline Protein Kinase A Signaling & -2.309 & 0.879 \\
\hline TREM1 Signaling & -2.236 & 1.45 \\
\hline Xenobiotic Metabolism AHR Signaling Pathway & -2.236 & 1.32 \\
\hline Necroptosis Signaling Pathway & -2.236 & 0.44 \\
\hline Type I Diabetes Mellitus Signaling & -2.121 & 4.69 \\
\hline Colorectal Cancer Metastasis Signaling & -2 & 3.58 \\
\hline $\begin{array}{l}\text { Role of Pattern Recognition Receptors in Recognition of Bacteria } \\
\text { and Viruses }\end{array}$ & -2 & 1.88 \\
\hline Role of IL-17F in Allergic Inflammatory Airway Diseases & -2 & 1.67 \\
\hline FAT10 Cancer Signaling Pathway & -2 & 1.5 \\
\hline NF- $\kappa \mathrm{B}$ Activation by Viruses & -2 & 0.783 \\
\hline VEGF Family Ligand-Receptor Interactions & -2 & 0.754 \\
\hline PI3K Signaling in B Lymphocytes & -2 & 0.567 \\
\hline Type II Diabetes Mellitus Signaling & -2 & 0.521 \\
\hline Tec Kinase Signaling & -2 & 0.399 \\
\hline Integrin Signaling & -2 & 0.353 \\
\hline
\end{tabular}


Supplementary Table S5: Most upregulated pathways among NELL1 KO clonal 143B cells by Ingenuity Pathway Analysis.

\begin{tabular}{lcc}
\hline Pathway & Z score & $\begin{array}{c}-\log \text { p- } \\
\text { value }\end{array}$ \\
\hline PPAR Signaling & 2.236 & 0.907 \\
LXR/RXR Activation & 2.121 & 1.86 \\
Mevalonate Pathway I & 2 & 3.57 \\
Superpathway of Geranylgeranyldiphosphate Biosynthesis I (via & 2 & 3.08 \\
Mevalonate) & 2 & 2.25 \\
Superpathway of Cholesterol Biosynthesis & 2 & 0.305 \\
PPAR $/$ RXR $\alpha$ Activation & 1.633 & 1.17 \\
T Cell Exhaustion Signaling Pathway & 1.342 & 0.618 \\
White Adipose Tissue Browning Pathway & & \\
\hline
\end{tabular}


Supplementary Table S6: Osteosarcoma related genes in clonal 143B cells (NELL1 KO vs. Vector control)

\begin{tabular}{|c|c|c|}
\hline Genes & $\log 2$ FC & p-value \\
\hline L1CAM & -1.2522 & 0.00801133 \\
\hline BIRC7 & -1.00944 & 0.196184 \\
\hline TNFRSF11B & -0.887322 & 0.0864929 \\
\hline VEGFA & -0.794242 & 0.0130133 \\
\hline MMP13 & -0.729936 & 0.107346 \\
\hline GAS7 & -0.675518 & 0.215202 \\
\hline IER3 & -0.64576 & 0.126576 \\
\hline MYCN & -0.56198 & 0.665071 \\
\hline S100A4 & -0.56186 & 0.0114564 \\
\hline BMP2 & -0.491486 & 0.313049 \\
\hline PMP22 & -0.47866 & $3.75 \mathrm{E}-05$ \\
\hline ERRFI1 & -0.405877 & 0.384411 \\
\hline TSPAN31 & -0.383682 & 0.0716137 \\
\hline CASP3 & -0.35849 & 0.00365317 \\
\hline CTSL & -0.2543 & 0.073668 \\
\hline SRC & -0.242787 & 0.315167 \\
\hline EXT1 & -0.220115 & 0.00830889 \\
\hline TP53 & -0.186245 & 0.00493618 \\
\hline KDM4C & -0.181524 & 0.419078 \\
\hline WNT10B & -0.16363 & 0.61923 \\
\hline HES1 & -0.10643 & 0.869479 \\
\hline CD44 & -0.101047 & 0.669849 \\
\hline TERF2 & -0.09173 & 0.621637 \\
\hline STAT3 & -0.07681 & 0.446684 \\
\hline BCL2L2 & -0.073435 & 0.531386 \\
\hline PLK1 & -0.0622225 & 0.622098 \\
\hline ABCG2 & -0.0363813 & 0.719462 \\
\hline CCNG1 & -0.03209 & 0.771689 \\
\hline ERBB2 & -0.0232025 & 0.827757 \\
\hline BAX & 0.0027575 & 0.97162 \\
\hline CHEK2 & 0.0217075 & 0.861121 \\
\hline MDM2 & 0.0256225 & 0.738639 \\
\hline MMP2 & 0.0502575 & 0.931319 \\
\hline RB1 & 0.0632125 & 0.519254 \\
\hline CDK4 & 0.121727 & 0.0655916 \\
\hline CDKN2D & 0.186561 & 0.364097 \\
\hline RECQL4 & 0.18896 & 0.343264 \\
\hline MCM4 & 0.21399 & 0.0494394 \\
\hline FOS & 0.21461 & 0.879092 \\
\hline PTH1R & 0.216413 & 0.292116 \\
\hline
\end{tabular}




\begin{tabular}{lll}
\hline Genes & Log2 FC & p-value \\
\hline PRIM1 & 0.27913 & $5.03 \mathrm{E}-05$ \\
CCNB2 & 0.280205 & 0.100503 \\
KIT & 0.310382 & 0.157051 \\
HMGB1 & 0.363268 & 0.00364131 \\
TNFRSF11A & 0.380036 & 0.588856 \\
BAD & 0.382345 & 0.0062038 \\
RMI1 & 0.487102 & 0.00328483 \\
CCNE1 & 0.553267 & 0.00877644 \\
CCN1 & 0.61587 & 0.184948 \\
SPARC & 0.620737 & 0.00929151 \\
E2F2 & 0.886565 & 0.00102943 \\
BCL2 & 0.950508 & 0.004066 \\
\hline
\end{tabular}


Supplementary Table S7: Most downregulated Gene Ontology terms among NELL1 KO clonal 143B cells by RNA sequencing.

\begin{tabular}{|c|c|c|}
\hline Gene Ontology & Count & p-value \\
\hline GO:0030198 extracellular matrix organization & 50 & $1.28 \mathrm{E}-17$ \\
\hline GO:0001525 angiogenesis & 41 & $9.90 \mathrm{E}-10$ \\
\hline GO:0030574 collagen catabolic process & 20 & $5.74 \mathrm{E}-09$ \\
\hline GO:0007155 cell adhesion & 62 & $1.26 \mathrm{E}-08$ \\
\hline GO:0035987 endodermal cell differentiation & 13 & $2.18 \mathrm{E}-08$ \\
\hline GO:0030334 regulation of cell migration & 18 & 2.03E-06 \\
\hline GO:0007229 integrin-mediated signaling pathway & 21 & $2.28 \mathrm{E}-06$ \\
\hline $\begin{array}{l}\text { GO:0070059 intrinsic apoptotic signaling pathway in response to } \\
\text { endoplasmic reticulum stress }\end{array}$ & 11 & $1.98 \mathrm{E}-05$ \\
\hline GO:0042981 regulation of apoptotic process & 31 & 2.09E-05 \\
\hline $\begin{array}{l}\text { GO: } 0010575 \text { positive regulation of vascular endothelial growth } \\
\text { factor production }\end{array}$ & 10 & $2.20 \mathrm{E}-05$ \\
\hline GO:0007165 signal transduction & 106 & 4.76E-05 \\
\hline GO:0022617 extracellular matrix disassembly & 16 & $5.48 \mathrm{E}-05$ \\
\hline GO:0042127 regulation of cell proliferation & 27 & $7.52 \mathrm{E}-05$ \\
\hline GO:0071260 cellular response to mechanical stimulus & 15 & $9.74 \mathrm{E}-05$ \\
\hline GO:0008285 negative regulation of cell proliferation & 45 & $1.20 \mathrm{E}-04$ \\
\hline $\begin{array}{l}\text { GO:0043123 positive regulation of I-kappaB kinase/NF-kappaB } \\
\text { signaling }\end{array}$ & 24 & $1.49 \mathrm{E}-04$ \\
\hline GO:0001666 response to hypoxia & 25 & $1.57 \mathrm{E}-04$ \\
\hline $\begin{array}{l}\text { GO:0051092 positive regulation of NF-kappaB transcription } \\
\text { factor activity }\end{array}$ & 21 & $1.96 \mathrm{E}-04$ \\
\hline GO:0048333 mesodermal cell differentiation & 6 & $3.04 \mathrm{E}-04$ \\
\hline GO:0043066 negative regulation of apoptotic process & 48 & $3.96 \mathrm{E}-04$ \\
\hline GO:0001570 vasculogenesis & 12 & $5.53 \mathrm{E}-04$ \\
\hline GO:0045766 positive regulation of angiogenesis & 18 & 7.04E-04 \\
\hline GO:0045599 negative regulation of fat cell differentiation & 10 & $9.02 \mathrm{E}-04$ \\
\hline GO:0043065 positive regulation of apoptotic process & 34 & $9.72 \mathrm{E}-04$ \\
\hline GO:0006915 apoptotic process & 55 & 0.001069105 \\
\hline
\end{tabular}


Supplementary Table S8: Most upregulated Gene Ontology terms among NELL1 KO clonal 143B cells by RNA sequencing.

\begin{tabular}{|c|c|c|}
\hline Gene Ontology & Count & p-value \\
\hline GO:0006260 DNA replication & 34 & $6.06 \mathrm{E}-11$ \\
\hline GO:0006695 cholesterol biosynthetic process & 16 & 1.17E-09 \\
\hline GO:0000732 strand displacement & 12 & $8.42 \mathrm{E}-08$ \\
\hline GO:0006281 DNA repair & 37 & 9.26E-08 \\
\hline GO:0000731 DNA synthesis involved in DNA repair & 13 & $3.37 \mathrm{E}-07$ \\
\hline GO:0036297 interstrand cross-link repair & 13 & $1.75 \mathrm{E}-05$ \\
\hline GO:0007067 mitotic nuclear division & 32 & $4.86 \mathrm{E}-05$ \\
\hline GO:0051301 cell division & 40 & 7.51E-05 \\
\hline GO:0008299 isoprenoid biosynthetic process & 7 & $7.66 \mathrm{E}-05$ \\
\hline GO:0000082 G1/S transition of mitotic cell cycle & 18 & 7.74E-05 \\
\hline GO:0007059 chromosome segregation & 14 & $1.28 \mathrm{E}-04$ \\
\hline $\begin{array}{l}\text { GO:0000083 regulation of transcription involved in G1/S } \\
\text { transition of mitotic cell cycle }\end{array}$ & 8 & 2.38E-04 \\
\hline GO:0055114 oxidation-reduction process & 56 & 3.94E-04 \\
\hline GO:0030324 lung development & 14 & 4.04E-04 \\
\hline GO:0006974 cellular response to DNA damage stimulus & 26 & 4.61E-04 \\
\hline GO:0003139 secondary heart field specification & 5 & $6.60 \mathrm{E}-04$ \\
\hline GO:0034080 CENP-A containing nucleosome assembly & 10 & $6.91 \mathrm{E}-04$ \\
\hline GO:0008283 cell proliferation & 38 & 7.65E-04 \\
\hline GO:0006099 tricarboxylic acid cycle & 8 & 0.001113854 \\
\hline $\begin{array}{l}\text { GO:0000122 negative regulation of transcription from RNA } \\
\text { polymerase II promoter }\end{array}$ & 63 & 0.001240728 \\
\hline GO:0001568 blood vessel development & 9 & 0.001307687 \\
\hline GO:0035264 multicellular organism growth & 13 & 0.00217589 \\
\hline GO:0010628 positive regulation of gene expression & 28 & 0.002846398 \\
\hline $\begin{array}{l}\text { GO:0060394 negative regulation of pathway-restricted SMAD } \\
\text { protein phosphorylation }\end{array}$ & 5 & 0.003868161 \\
\hline GO:0045746 negative regulation of Notch signaling pathway & 7 & 0.005722524 \\
\hline
\end{tabular}


Supplementary Table S9: Most downregulated Gene Ontology terms among NELL1 KO clonal 143B cells by proteomic analysis.

\begin{tabular}{|c|c|c|}
\hline Gene Ontology & Count & p-value \\
\hline GO:0043066 negative regulation of apoptotic process & 13 & 3.17E-08 \\
\hline GO:0008284 positive regulation of cell proliferation & 13 & 4.13E-08 \\
\hline GO:0000082 G1/S transition of mitotic cell cycle & 8 & $5.11 \mathrm{E}-08$ \\
\hline GO:0046777 protein autophosphorylation & 9 & $1.11 \mathrm{E}-07$ \\
\hline GO:0051726 regulation of cell cycle & 8 & $1.97 \mathrm{E}-07$ \\
\hline GO:0042127 regulation of cell proliferation & 8 & $2.92 \mathrm{E}-06$ \\
\hline GO:0008283 cell proliferation & 10 & $3.60 \mathrm{E}-06$ \\
\hline GO:0018105 peptidyl-serine phosphorylation & 7 & 4.01E-06 \\
\hline GO:0042493 response to drug & 9 & $8.05 \mathrm{E}-06$ \\
\hline GO:0032355 response to estradiol & 6 & $1.40 \mathrm{E}-05$ \\
\hline GO:0008285 negative regulation of cell proliferation & 9 & $5.36 \mathrm{E}-05$ \\
\hline $\begin{array}{l}\text { GO:0000083 regulation of transcription involved in G1/S } \\
\text { transition of mitotic cell cycle }\end{array}$ & 4 & $6.26 \mathrm{E}-05$ \\
\hline $\begin{array}{l}\text { GO:0000122 negative regulation of transcription from RNA } \\
\text { polymerase II promoter }\end{array}$ & 11 & $1.37 \mathrm{E}-04$ \\
\hline GO:0006281 DNA repair & 7 & $1.41 \mathrm{E}-04$ \\
\hline GO:0035264 multicellular organism growth & 5 & $1.56 \mathrm{E}-04$ \\
\hline GO:0018108 peptidyl-tyrosine phosphorylation & 6 & $1.68 \mathrm{E}-04$ \\
\hline GO:0009636 response to toxic substance & 5 & $1.97 \mathrm{E}-04$ \\
\hline $\begin{array}{l}\text { GO:0007169 transmembrane receptor protein tyrosine kinase } \\
\text { signaling pathway }\end{array}$ & 5 & $3.14 \mathrm{E}-04$ \\
\hline GO:0006469 negative regulation of protein kinase activity & 5 & $3.53 \mathrm{E}-04$ \\
\hline GO:0035556 intracellular signal transduction & 8 & $4.09 \mathrm{E}-04$ \\
\hline GO:0045471 response to ethanol & 5 & $4.42 \mathrm{E}-04$ \\
\hline GO:0048015 phosphatidylinositol-mediated signaling & 5 & $4.58 \mathrm{E}-04$ \\
\hline GO:0030335 positive regulation of cell migration & 5 & 0.003505609 \\
\hline GO:0045747 positive regulation of Notch signaling pathway & 3 & 0.005587098 \\
\hline GO:0034446 substrate adhesion-dependent cell spreading & 3 & 0.007358625 \\
\hline
\end{tabular}


Supplementary Table S10: Most upregulated Gene Ontology terms among NELL1 KO clonal 143B cells by proteomic analysis.

\begin{tabular}{|c|c|c|}
\hline Gene Ontology & Count & p-value \\
\hline GO:0043065 positive regulation of apoptotic process & 8 & $3.54 \mathrm{E}-07$ \\
\hline GO:0071260 cellular response to mechanical stimulus & 5 & 4.78E-06 \\
\hline GO:0071456 cellular response to hypoxia & 5 & $1.59 \mathrm{E}-05$ \\
\hline $\begin{array}{l}\text { GO:0048661 positive regulation of smooth muscle cell } \\
\text { proliferation }\end{array}$ & 4 & 1.19E-04 \\
\hline GO:0001666 response to hypoxia & 5 & $1.55 \mathrm{E}-04$ \\
\hline GO:0006915 apoptotic process & 7 & 2.33E-04 \\
\hline GO:0042981 regulation of apoptotic process & 5 & $3.51 \mathrm{E}-04$ \\
\hline GO:0008637 apoptotic mitochondrial changes & 3 & 4.19E-04 \\
\hline GO:0043066 negative regulation of apoptotic process & 6 & 7.04E-04 \\
\hline $\begin{array}{l}\text { GO: } 0045944 \text { positive regulation of transcription from RNA } \\
\text { polymerase II promoter }\end{array}$ & 8 & 7.19E-04 \\
\hline GO:0098609 cell-cell adhesion & 5 & 8.69E-04 \\
\hline GO:0097193 intrinsic apoptotic signaling pathway & 3 & 0.001053376 \\
\hline $\begin{array}{l}\text { GO: } 1900740 \text { positive regulation of protein insertion into } \\
\text { mitochondrial membrane involved in apoptotic signaling pathway }\end{array}$ & 3 & 0.001053376 \\
\hline GO:0042493 response to drug & 5 & 0.001330423 \\
\hline $\begin{array}{l}\text { GO:0008630 intrinsic apoptotic signaling pathway in response to } \\
\text { DNA damage }\end{array}$ & 3 & 0.002574001 \\
\hline GO:0042542 response to hydrogen peroxide & 3 & 0.003023949 \\
\hline GO:0008285 negative regulation of cell proliferation & 5 & 0.003479001 \\
\hline GO:0001525 angiogenesis & 4 & 0.005342541 \\
\hline GO:0007584 response to nutrient & 3 & 0.006262053 \\
\hline GO:0032869 cellular response to insulin stimulus & 3 & 0.006763636 \\
\hline GO:0030307 positive regulation of cell growth & 3 & 0.008002639 \\
\hline GO:0072656 maintenance of protein location in mitochondrion & 2 & 0.008014682 \\
\hline $\begin{array}{l}\text { GO:0072655 establishment of protein localization to } \\
\text { mitochondrion }\end{array}$ & 2 & 0.009610179 \\
\hline GO:0032287 peripheral nervous system myelin maintenance & 2 & 0.011203204 \\
\hline GO:0016032 viral process & 4 & 0.011917614 \\
\hline
\end{tabular}


Supplementary Table S11. Summary of NELL1 and FN1 immunostaining in biopsy samples of high grade conventional osteosarcoma.

\begin{tabular}{ccc}
\hline \multirow{2}{*}{ Sample } & \multicolumn{2}{c}{ Biopsy (\%Area) } \\
\cline { 2 - 3 } & NELL1 & FN1 \\
\hline$\# 1$ & 38.6 & 50.5 \\
$\# 2$ & 28.2 & 38.7 \\
$\# 3$ & 23.6 & 18.4 \\
$\# 4$ & 18.1 & 21.1 \\
$\# 5$ & 13.9 & 11.0 \\
\hline
\end{tabular}


Supplementary Table S12. Antibodies used.

\begin{tabular}{|c|c|c|c|}
\hline Antibody & Company & Catalog \# & Use \\
\hline Rabbit anti-CD31 & Abcam & ab28364 & IF \\
\hline Rat anti-Mouse CD31 & BD Pharmingen & 551262 & $\mathrm{~F}$ \\
\hline Mouse anti-Human CD44 & BD Pharmingen & 561289 & $\mathrm{~F}$ \\
\hline Rat anti-Mouse CD45 & BD Pharmingen & 559864 & $\mathrm{~F}$ \\
\hline Mouse anti-Human CD73 & BD Pharmingen & 561014 & $\mathrm{~F}$ \\
\hline Mouse anti-Human CD90 & BD Pharmingen & 555595 & $\mathrm{~F}$ \\
\hline Mouse anti-Human CD105 & BD Pharmingen & 562380 & $\mathrm{~F}$ \\
\hline Rabbit anti-FAK & Abcam & ab40794 & $\mathrm{IF} / \mathrm{WB}$ \\
\hline Rabbit anti-pFAK & Abcam & ab81298 & $\mathrm{IF} / \mathrm{WB} / \mathrm{ICC}$ \\
\hline Rabbit anti-Fibronectin & Abcam & $\mathrm{ab} 2413$ & IF \\
\hline Rabbit anti-GAPDH & Abcam & ab9485 & WB \\
\hline Rabbit anti-Ki67 & Abcam & ab15580 & IF \\
\hline Mouse anti-Laminin & Cell signaling & $4777 \mathrm{~S}$ & IF \\
\hline Mouse anti-human NELL1 & R\&D system & MAB54871 & $\mathrm{ICC} / \mathrm{IF}$ \\
\hline $\begin{array}{l}\text { Anti-rabbit IgG, HRP-linked } \\
\text { Antibody }\end{array}$ & $\begin{array}{l}\text { Cell Signaling } \\
\text { Technology }\end{array}$ & 7074 & WB \\
\hline Goat anti-Mouse AF488 & Abcam & ab150117 & IF \\
\hline Goat anti-Rabbit AF488 & Abcam & ab150077 & IF \\
\hline Goat anti-Rabbit DyLight 594 & Vector Laboratories & DI-1594 & IF \\
\hline Donkey anti-Goat AF647 & Abcam & ab150135 & IF \\
\hline Goat anti-Mouse AF647 & Abcam & ab150119 & IF \\
\hline Goat anti-Rabbit AF647 & Abcam & ab150079 & IF \\
\hline Goat anti-Rat AF647 & Abcam & ab150167 & IF \\
\hline
\end{tabular}


Supplementary Table S13. CRISPR/Cas9 sgRNA and primer sequences.

\begin{tabular}{|c|c|c|}
\hline CRISPR/Cas9 & \multicolumn{2}{|c|}{ Sequence } \\
\hline $\begin{array}{c}\text { Knockout } \\
\text { Negative } \\
\text { control }\end{array}$ & 5'-ATACTGTCCATTCGAGAAC-3' \\
\hline $\begin{array}{c}\text { Primers } \\
\text { Genes } \\
\text { (human) }\end{array}$ & 5'-CGCGATAGCGCGAATATATT-3' \\
\hline NELL1 (T7EI) & TTGAATGAATGCAGCTGTAGGG & GATTGGTCCTTGGAGAGCAAAC \\
\hline NELL1 & TGGCCACTGTACAGCAGAAG & CAAGAAAGCCACTTTGACCA \\
\hline GAPDH & CTGGGCTACACTGAGCACC & AAGTGGTCGTTGAGGGCAATG \\
\hline
\end{tabular}


Supplementary Table S14. Summary of osteosarcoma cell implantation models.

\begin{tabular}{|c|c|c|c|c|c|}
\hline Study & Cell type & Injection location & $\begin{array}{l}\text { Cell \# per } \\
\text { animal }\end{array}$ & $\begin{array}{c}\text { \# of } \\
\text { animals }\end{array}$ & Endpoint \\
\hline \multirow{2}{*}{$\begin{array}{l}\text { Tumor } \\
\text { size }\end{array}$} & Vector control 143B & Tibial periosteum & $1 \mathrm{M}$ & 8 & $28 \mathrm{~d}$ \\
\hline & Nell1 KO 143B, clone \#2 & Tibial periosteum & $1 \mathrm{M}$ & 8 & $28 \mathrm{~d}$ \\
\hline \multirow{2}{*}{$\begin{array}{l}\text { Overall } \\
\text { survival }\end{array}$} & Vector control 143B & Tibial periosteum & $1 \mathrm{M}$ & 10 & Until moribund \\
\hline & Nell1 KO 143B, clone \#2 & Tibial periosteum & $1 \mathrm{M}$ & 10 & Until moribund \\
\hline \multirow{2}{*}{$\begin{array}{l}\text { Pulmonary } \\
\text { metastasis }\end{array}$} & Vector control 143B & $\begin{array}{l}\text { Intravenous } \\
\text { (tail vein) }\end{array}$ & $1.5 \mathrm{M}$ & 8 & $28 \mathrm{~d}$ \\
\hline & Nell1 KO 143B, clone \#2 & $\begin{array}{l}\text { Intravenous } \\
\text { (tail vein) }\end{array}$ & $1.5 \mathrm{M}$ & 8 & $28 \mathrm{~d}$ \\
\hline \multirow{2}{*}{$\begin{array}{l}\text { Tumor } \\
\text { size }\end{array}$} & Vector control 143B & Tibial periosteum & $1 \mathrm{M}$ & 9 & $28 \mathrm{~d}$ \\
\hline & Nell1 KO 143B, clone \#4 & Tibial periosteum & $1 \mathrm{M}$ & 13 & $28 \mathrm{~d}$ \\
\hline \multirow{2}{*}{$\begin{array}{l}\text { Tumor } \\
\text { free } \\
\text { survival }\end{array}$} & $\begin{array}{c}p 53^{\mathrm{fl} / \mathrm{fl}} ; R b^{\mathrm{fl} / \mathrm{fl}} ; \mathrm{Cre}^{+}(\mathrm{DKO}) \\
\text { mouse BMSC }\end{array}$ & Tibial periosteum & $1 \mathrm{M}$ & 12 & $\begin{array}{l}28 \mathrm{~d} \text { after tumor } \\
\text { observed }\end{array}$ \\
\hline & $\begin{array}{c}p 53^{\mathrm{fl} / \mathrm{fl}} ; R b^{\mathrm{fl} / \mathrm{fl}} ; N e l l 1^{\mathrm{fl} / \mathrm{fl} l} ; \mathrm{Cre}^{+} \\
(\mathrm{TKO}) \text { mouse BMSC }\end{array}$ & Tibial periosteum & $1 \mathrm{M}$ & 12 & $\begin{array}{l}28 \mathrm{~d} \text { after tumor } \\
\text { observed }\end{array}$ \\
\hline
\end{tabular}




\section{Data availability}

RNA sequencing data is freely available within the NCBI GEO database (GSE182703).

Proteomic data is submitted as a separate Excel file. 